\title{
REVIEW
}

Open Access

\section{Choice architecture interventions to change physical activity and sedentary behavior: a systematic review of effects on intention, behavior and health outcomes during and after intervention}

\author{
Lorraine L. Landais ${ }^{1 *}$, Olga C. Damman ${ }^{1}$, Linda J. Schoonmade², Danielle R. M. Timmermans',
}

Evert A. L. M. Verhagen ${ }^{1,3}$ and Judith G. M. Jelsma ${ }^{1}$

\begin{abstract}
Background: Choice architecture interventions, which subtly change the environment in which individuals make decisions, can be used to promote behavior change. This systematic review aimed to summarize studies on microenvironmental choice architecture interventions that encouraged physical activity or discouraged sedentary behavior in adults, and to describe the effectiveness of those interventions on these behaviors - and on related intentions or health outcomes - in presence of the intervention and after removal of the intervention (i.e. postintervention, regardless of the time elapsed).

Methods: We systematically searched PubMed, Embase, PsycINFO and the Cochrane Library for (quasi) experimental studies published up to December 2019 that evaluated the effect of choice architecture interventions on physical activity and sedentary behavior, as well as on intentions and health outcomes related to physical activity/sedentary behavior. Studies that combined choice architecture techniques with other behavior change techniques were excluded. All studies were screened for eligibility, relevant data was extracted and two independent reviewers assessed the methodological quality using the QualSyst tool.

\footnotetext{
* Correspondence: I.landais@amsterdamumc.nl

'Department of Public and Occupational Health, Amsterdam UMC, Vrije Universiteit Amsterdam, Amsterdam Public Health research institute, Van der Boechorststraat 7, NL-1081 BT Amsterdam, The Netherlands

Full list of author information is available at the end of the article
}

C C The Author(s). 2020 Open Access This article is licensed under a Creative Commons Attribution 4.0 International License, which permits use, sharing, adaptation, distribution and reproduction in any medium or format, as long as you give appropriate credit to the original author(s) and the source, provide a link to the Creative Commons licence, and indicate if changes were made. The images or other third party material in this article are included in the article's Creative Commons licence, unless indicated otherwise in a credit line to the material. If material is not included in the article's Creative Commons licence and your intended use is not permitted by statutory regulation or exceeds the permitted use, you will need to obtain permission directly from the copyright holder. To view a copy of this licence, visit http://creativecommons.org/licenses/by/4.0/. The Creative Commons Public Domain Dedication waiver (http://creativecommons.org/publicdomain/zero/1.0/) applies to the data made available in this article, unless otherwise stated in a credit line to the data. 
(Continued from previous page)

Results: Of the 9609 records initially identified, 88 studies met our eligibility criteria. Most studies $(n=70)$ were of high methodologic quality. Eighty-six studies targeted physical activity, predominantly stair use, whereas two studies targeted sedentary behavior, and one targeted both behaviors. Intervention techniques identified were prompting ( $n=53)$, message framing $(n=24)$, social comparison $(n=12)$, feedback $(n=8)$, default change $(n=1)$ and anchoring $(n=1)$. In presence of the intervention, $68 \%$ of the studies reported an effect of choice architecture on behavior, whereas after removal of the intervention only $47 \%$ of the studies reported a significant effect. For all choice architecture techniques identified, except for message framing, the majority of studies reported a significant effect on behavioral intentions or behavior in presence of the intervention.

Conclusions: The results suggest that prompting can effectively encourage stair use in adults, especially in presence of a prompt. The effectiveness of the choice architecture techniques social influence, feedback, default change and anchoring cannot be assessed based on this review. More (controlled) studies are needed to assess the (sustained) effectiveness of choice architecture interventions on sedentary behavior and other types of physical activity than stair use.

Keywords: Choice architecture, Nudging, Behavioral economics, Environmental intervention, Health behavior, Physical activity, Sedentary behavior, Public health

\section{Introduction}

An important public health challenge of the twenty-first Century is to increase individuals' levels of physical activity and to reduce their sedentary behavior. One third of the adult population worldwide does not reach the public health guidelines for recommended levels of physical activity [1], and almost one in five Europeans report sitting more than $7.5 \mathrm{~h}$ per day [2]. This is worrisome, given that physical inactivity and excessive sedentary behavior independently increase the risk of non-communicable diseases, and can shorten life expectancy [3-7].

A promising approach to break individuals' unhealthy habits and promote healthy behavior (e.g. increase physical activity and decrease sedentary behavior) is to make subtle changes to the micro-environment in which individuals make decisions, an approach termed 'choice architecture' or 'nudging' [8-12]. The micro-environment refers to relatively small settings, such as homes and workplaces [13, 14]. Choice architecture is built on the principle that human decision making is often based on automatic and/or heuristic thought processes, rather than effortful deliberate processes alone [15-18]. These automatic thought processes play a considerable role in daily behavior, including habits [19]. Habits are context-response associations in memory that develop as individuals repeat behavior in daily life [9]; once a habit is formed, merely perceiving a certain context can automatically trigger the associated behavioral response [17].

Choice architecture interventions are applied in the physical, social and/or information environment [10, 15, 20]. In the physical environment, for instance, individuals can be prompted to take the stairs instead of the elevator through footprints on the floor that lead to the stairwell [21]. An example of an intervention in the social environment is the use of social norms, which can be either descriptive (i.e. providing information about the behavior of others) or injunctive (i.e. providing information about others' approval) [22]. Finally, the information environment includes interventions that alter the way in which messages are presented or framed, for example in terms of gains (i.e. emphasizing the benefits of the desired behavior) or losses (i.e. emphasizing consequences of the undesired behavior) $[11,20,23,24]$.

In recent decades, choice architecture has gained momentum in the field of public health and health promotion $[10,12,25,26]$; however, its theoretical principles originate in a long tradition of judgment and decision making research $[16,20,27]$. Past research has demonstrated that choice architecture interventions can effectively change behavior in a variety of health domains [10]; however, studies on choice architecture in the domain of physical activity and sedentary behavior have received relatively little attention compared to, for example, dietary behavior (e.g. [28-30]). The current review will therefore focus on choice architecture in the domain of physical activity and sedentary behavior.

Two scoping reviews have previously provided an overview of studies using choice architecture interventions to promote physical activity [14, 31], though both reviews only sparsely reported on the effectiveness of the interventions on physical activity. Moreover, there is still a lack of insight regarding the extent to which choice architecture interventions can effectuate durable behavior change after removal of the intervention [15]. It is important to make a distinction between initial behavior change and maintenance of behavior change [32], especially since interventions that effectuate behavior change during the intervention often fail to maintain this change in the long term after removal of the intervention $[8,9]$. Finally, a more extensive insight 
into the effectiveness of choice architecture interventions could be obtained by looking at changes in behavioral intentions and health outcomes related to physical activity and sedentary behavior. It should be noted, however, that changes in intentions do not always equate to changes in behavior [33].

The aim of the current systematic literature review is therefore to summarize studies on micro-environmental choice architecture interventions that encourage physical activity or discourage sedentary behavior in adults, and to describe the effectiveness of those interventions on these behaviors - and on related intentions or health outcomes - in presence of the intervention and after removal of the intervention (i.e. post-intervention, regardless of the time elapsed).

\section{Methods}

This systematic literature review was reported in accordance with the Preferred Reporting Items for Systematic Reviews and Meta-analyses (PRISMA) guidelines [34]. The review was prospectively registered with the International Prospective Register of Systematic Reviews (PROSPERO) on October 26, 2018 (PROSPERO 2018: CRD42018102999).

\section{Definitions}

For the purpose of this review, choice architecture interventions were defined as interventions that alter the presentation of a choice through information or through the physical or social micro-environment in which individuals make decisions, with the intention of changing health-related choices and behaviors. This definition was based on the descriptions of choice architecture by Hollands et al. (2013), Thaler and Sunstein (2008) and Münscher et al. (2016) [10, 11, 14]. In addition, we specified three types of environments in which choice architecture interventions can be applied: the physical, social and information environment. We did not consider interventions that (a) are conducted in the macroenvironment, such as the construction of parks and bicycle paths in a city, (b) limit freedom of choice, such as mandates, (c) make use of economic instruments, such as financial incentives, (d) have commercial purposes or (e) solely aim to raise awareness $[10,14]$.

The outcome measures of interest were (a) the intention or motivation to be physically active/less sedentary; (b) behavioral measures of physical activity or sedentary behavior; and (c) anthropometric and cardiovascular health outcomes (e.g. change in body weight and blood pressure). Outcomes could be self-reported, measured by wearable health monitoring devices, or assessed through biometric measurements.

\section{Search strategy}

In collaboration with a medical librarian (LS), a comprehensive search was performed in the bibliographic databases PubMed, Embase, PsycINFO (via Ebsco) and the Cochrane Library from inception to December 13, 2019. Search terms included controlled terms $\mathrm{MeSH}$ in Pubmed, Emtree in Embase and thesaurus terms is PsycINFO) as well as free text terms. In terms of Population, Intervention, Comparison, Outcome and Study design (PICOS), the search strategy included terms for Intervention (e.g. 'choice architecture'), Outcome (e.g. 'health behavior') and Study design (e.g. 'randomized controlled trial'); Population and Comparison were manually checked during the article selection phase. Search terms were used as index terms or as free-text words; for most terms, synonyms and closely related words were included. A search filter was used to limit for experimental and quasi-experimental studies. The search was performed without date or language restriction. The full search strategies for all databases can be found in Additional file 1. Retrieved articles were imported in EndNote and subsequently de-duplicated using the Bramer method [35]. Additional references were obtained by hand-searching reference lists of included articles (backward search) and by citation search for included articles (forward search).

\section{Eligibility criteria}

Articles were eligible for inclusion if they (a) investigated the effect of a choice architecture intervention on physical activity or sedentary behavior, the intention to engage in these behaviors and/or associated health outcomes; (b) studied an adult population (aged 18 years and over); and (c) contained an experimental or quasiexperimental study design. To determine whether the studies derived from the search contained a choice architecture intervention, we used the abovementioned operational definition of this term and the taxonomy of choice architecture techniques from Münscher et al. (2016) [11]. Following from this, interventions did not necessarily need to be labeled as 'choice architecture' by the original studies. Articles were excluded if (a) they were written in a language other than English; (b) the study population consisted entirely of individuals with a communicable disease, psychiatric disorder or cancer; or (c) a combination of choice architecture and other behavioral change techniques was used, because this would interfere with our aim to attribute the effect to the choice architecture component(s) separately.

\section{Article selection}

Rayyan, an internet-based software program that facilitates collaboration among reviewers, was used for the study selection process [36]. As a first step, this process 
consisted of screening all titles against the eligibility criteria, which was done by one researcher (LL). Subsequently, abstracts of the remaining articles were screened by two researchers independently. In this phase, one researcher (LL) covered all articles, and two other researchers (JJ, OD) both covered a different half of the articles. The degree of inter-rater agreement was 81.3\% for abstract assessments. One researcher (LL) subsequently screened all full-texts against the eligibility criteria. In case of doubt, two other researchers (JJ, OD) were consulted. Disagreements between reviewers were resolved through discussion.

\section{Data extraction}

One researcher (LL) extracted data from the included studies using a standardized form. Extracted data included study design, setting, target behavior, population characteristics, sample size, details of the intervention and comparison condition, intervention technique, type of environment (physical, social and/or information environment), outcome measurement and findings in presence of the intervention and after removal of the intervention. Outcomes were categorized as in presence of the intervention if the intervention was present at the moment of measurement, or if the effect was measured directly after exposure to the intervention. Outcomes were categorized as after removal of the intervention if the intervention was no longer present at the moment of measurement. An exception to this applied to interventions conducted in the information environment, since these interventions were typically of much shorter duration. For these interventions, the following cut-off points were used: in presence of the intervention: measurements directly after exposure to the intervention up to 1 week after exposure to the intervention; after removal of the intervention: measurements $>1$ week post-intervention.

Intervention effectiveness was determined by the statistical significance of the effect (significant/not significant) as reported by the original studies. Unless otherwise specified, significant effects reported in the current review refer to effects in the healthy direction. For studies with multiple post-intervention measurements, we reported the outcomes of the measurement most distant from the end of the intervention. Studies that reported both significant and not significant effects on the same outcome variable (e.g. a significant effect on physical activity for women, but not for men) were labeled 'mixed effects'. Note that in this review, significant effects in experimental studies with pre- and post- measures refer to a significant increase in the intervention condition compared to the comparison condition over time (i.e. baseline compared to follow-up), whereas significant effects in studies with a factorial design refer to a significant increase in one condition compared to another condition.

\section{Quality assessment}

The methodological quality assessment served to inform interpretation of findings, rather than to determine study eligibility. Study quality was assessed independently by two researchers (LL and JJ) using the QualSyst tool from Kmet el al. (2004) [37], allowing assessment of both experimental and quasi-experimental studies. The tool consisted of fourteen items to be scored 'Yes' [2], 'Partial' [1], 'No' (0) or 'Not applicable' (N/A), depending on the degree to which specific criteria were met or reported. Aspects covered include quality of study design, confounders, blinding, selection bias and misclassification bias. Discrepancies in assessments between reviewers were resolved through discussion. For each study, a summary score was calculated by summing the total score obtained and dividing it by the total possible score. A quality score of $\geq .75$ indicates strong quality, a score between .55 and .75 moderate quality, and a score $\leq .55$ weak quality.

\section{Data synthesis}

High heterogeneity between studies with regard to study design, intervention characteristics, type of outcome measure and outcome measure assessment prevented performance of a meta-analysis. Instead, we synthesized extracted data by narratively summarizing the characteristics, quality and findings of the included studies. After summarizing the content of interventions, one researcher (LL) inductively identified different intervention techniques by checking the intervention components described in the studies against our operational definition of choice architecture and the choice architecture techniques described by Münscher et al. [11]. Techniques reported in the current review were termed in line with the general choice architecture literature as much as possible (e.g. [10]). The synthesis was structured around (a) the choice architecture techniques identified and (b) the effectiveness of interventions in changing intentions, behaviors or health outcomes in presence of the intervention and after removal of the intervention.

\section{Results \\ Study selection}

Figure 1 shows the flow diagram of the study selection process. The database searches initially identified 6841 records, of which 4798 remained after removal of duplicates from the database searches. Backward and forward citation searches identified 2768 records. A total of 202 full-text articles were assessed for eligibility. Eighty-four articles were included in this review, comprising 88 unique studies. 


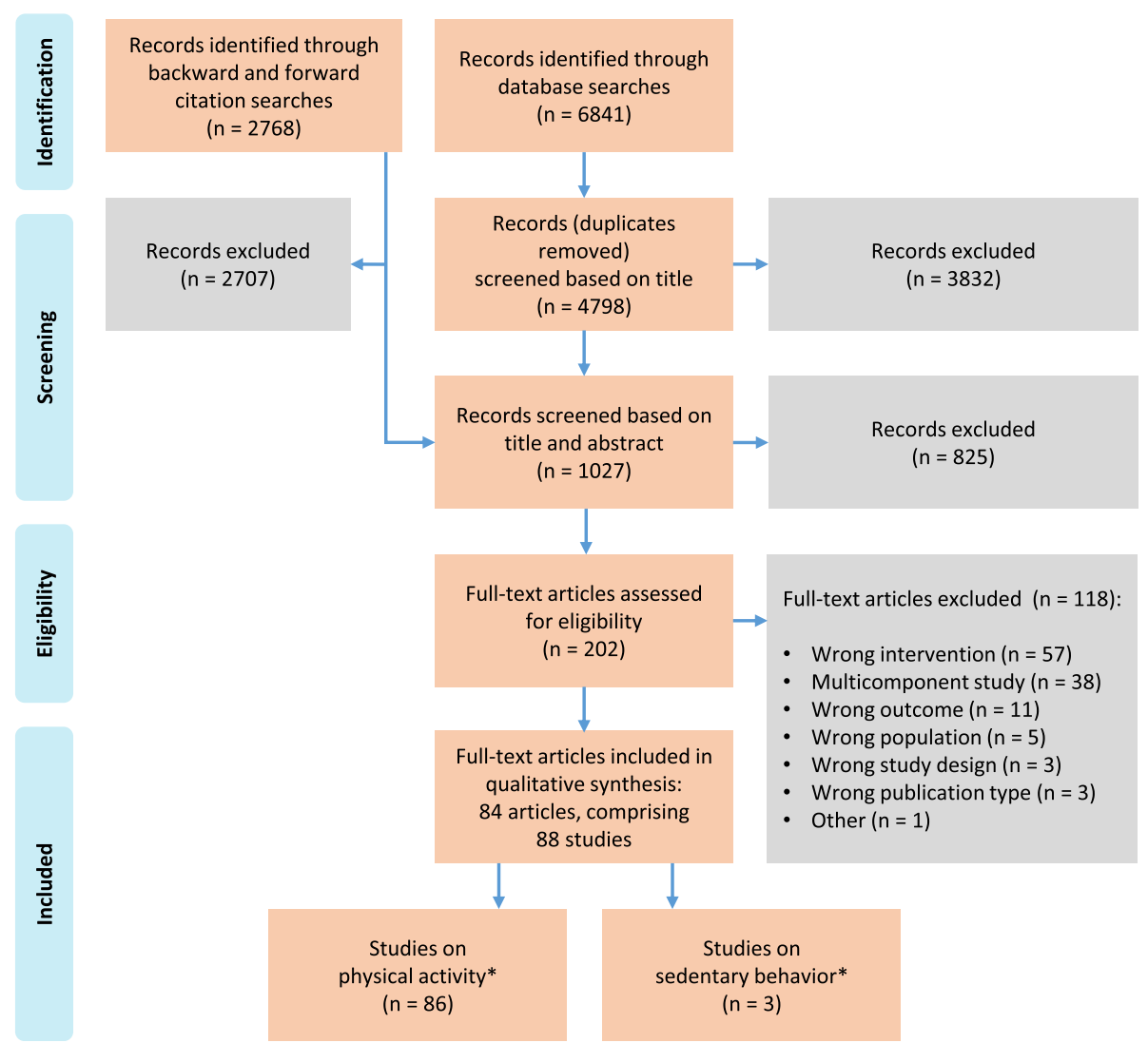

Fig. 1 PRISMA flow diagram of the study selection process. * One study measured both physical activity and sedentary behavior [38]

\section{Study characteristics}

Table 1 summarizes study characteristics of the included studies. Studies were conducted in the United States $(n=38)$, Europe $(n=37)$, Canada $(n=6)$, China $(n=4)$ or Australia $(n=3)$. The number of participants across included studies ranged from 30 [47] to 9729 [116].

\section{Design and setting}

Thirty-three studies applied an experimental research design [38, 40, 51, 61, 86-101, 103, 104, 106-108, 111, $113,115,117-120]^{1}$ : a pretest-posttest design $(n=18)$, factorial design $(n=11)$, cluster randomized design $(n=$ $2)$, post-test only design $(n=1)$ or cross-over design $(n=1)$. The remaining 56 studies used a quasiexperimental design $(38,40-49,51-59,61-84,101,104$, $108,110,112,114,116,121)^{1}$; either a time-series design $(n=45)$, pretest-posttest design $(n=7)$ or post-test only design $(n=3)$. Field experiments were most frequently conducted at the workplace $(n=19)(40,42,43,53,56$, $57,60,63,64,68,73,78-80,108,110,112,116,121)^{1}$, followed by public transport locations $(n=11)(38,45,48$, $55,65,69,71,74,76,77)^{1}$, university campuses $(\mathrm{n}=11)$

\footnotetext{
${ }^{1}$ The number of studies reported does not always match the number of citations, because four articles covered two studies.
}

$[48,50,52,53,55,59,62,63,70,71,76,114]$, shopping malls $(n=10)(41,48,65-67,81-84,110)^{1}$, hospitals $(n=2)[45,73]$, and the home environment $(n=2)$ [60, 111]. A total of 23 studies were conducted in a laboratory setting $(85-87,89-103,105-107)^{1}$. The remaining studies implemented an intervention through a mobile phone application or website $(n=8)[38,47,113$, 115-118, 120], mobile text messages $(n=2)[51,89]$ or e-mail $(n=2)[40,119]$.

\section{Study outcome}

Of the included studies, 86 studies targeted physical activity and within these studies, seventeen measured the intention to be more physically active $[86,87,89-94,96$, $99,104-108,122]^{1}, 74$ measured physical activity behavior $[38,39,41-53,55-69,71-85,87,89,90,93-98$, $100-103,105,106,109-120]^{1}$ and four measured health outcomes [40, 54, 60, 111]. A total of three studies targeted sedentary behavior, of which one measured the intention to be less sedentary [121] and two measured sedentary behavior [38, 47]; none of the studies measured health outcomes. Individuals' intentions to become physically active or less sedentary were usually measured by one to three questionnaire items on a 5-, 6- or 7point scale. Physical activity was assessed with objective 


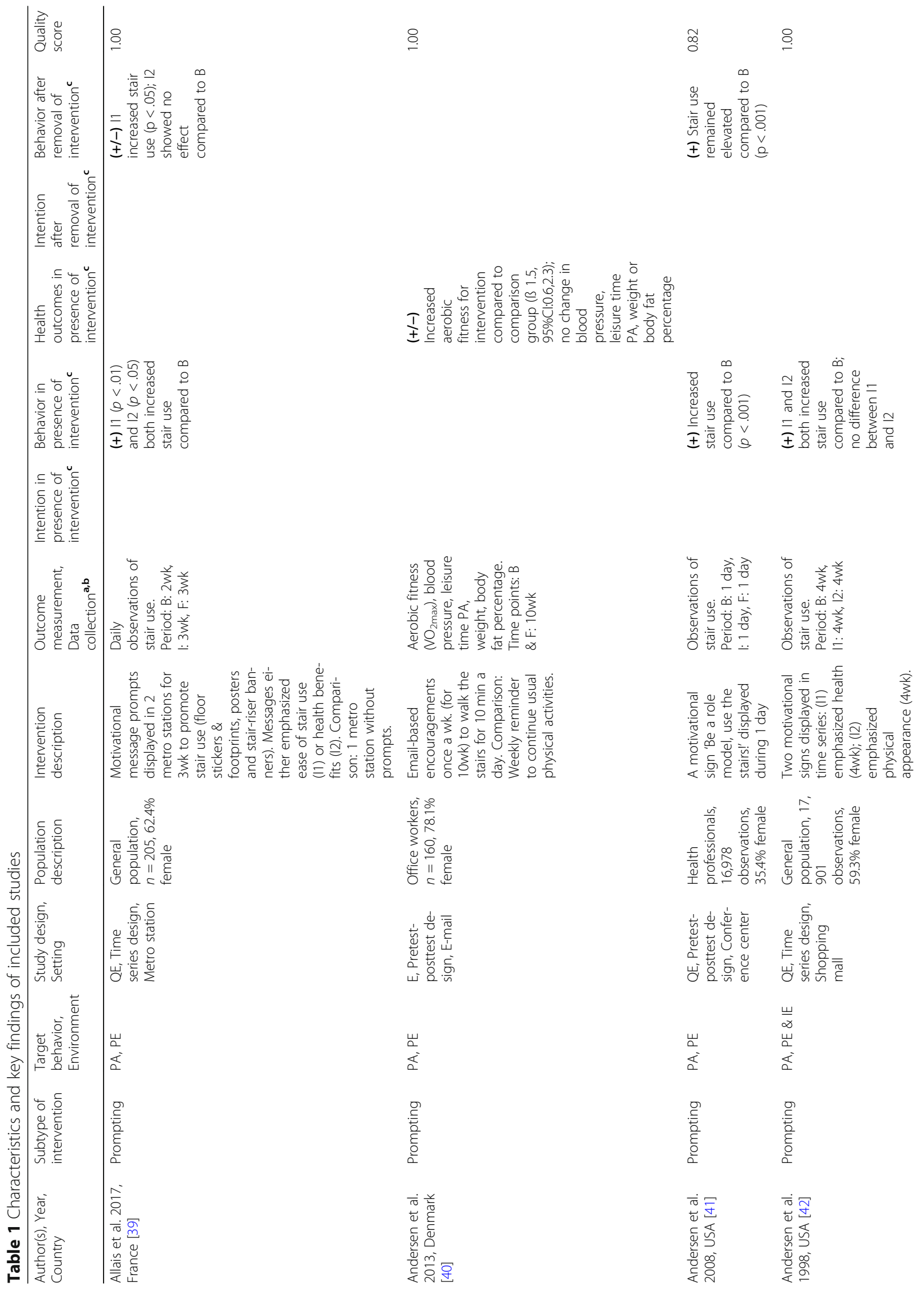




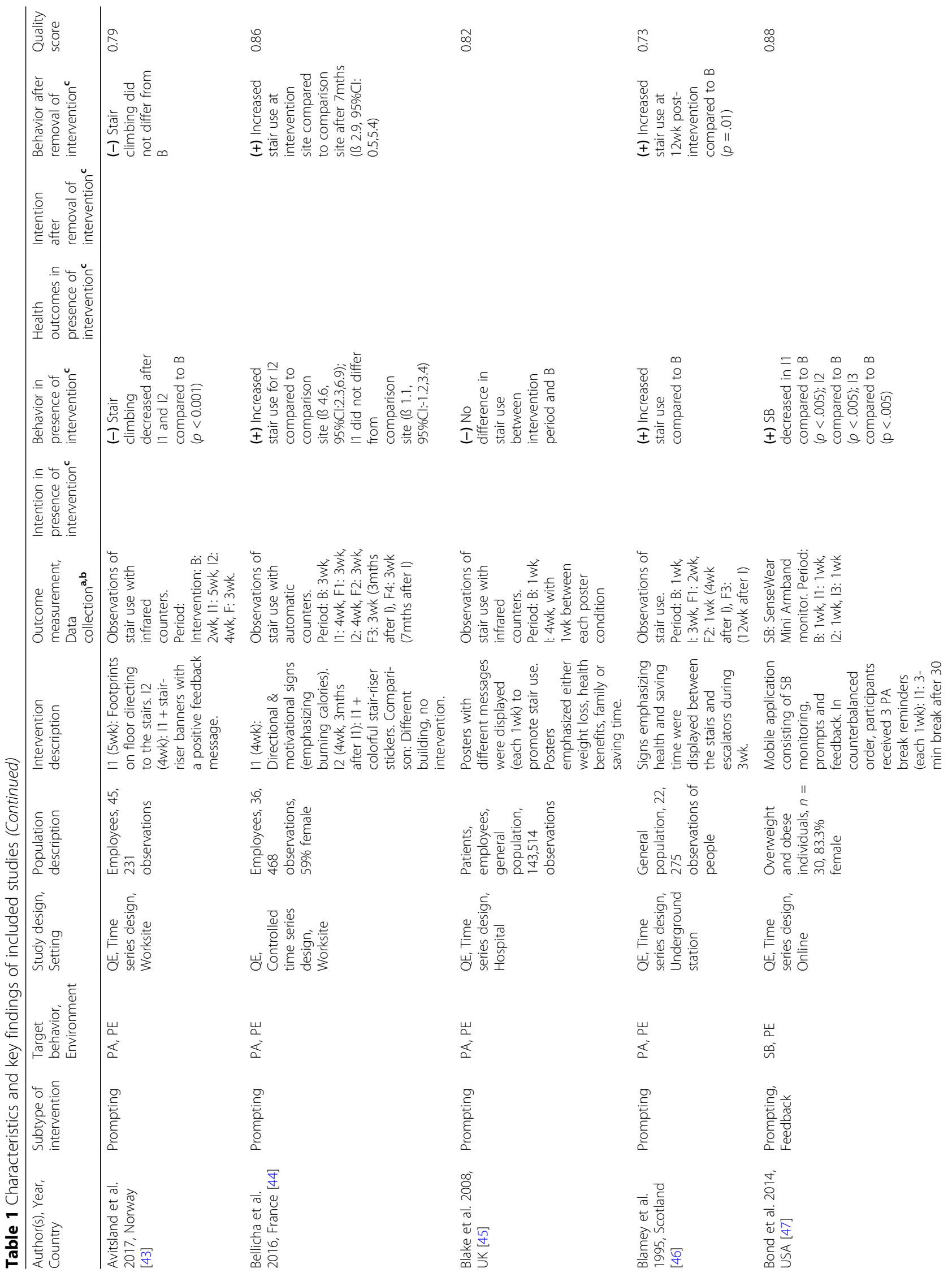




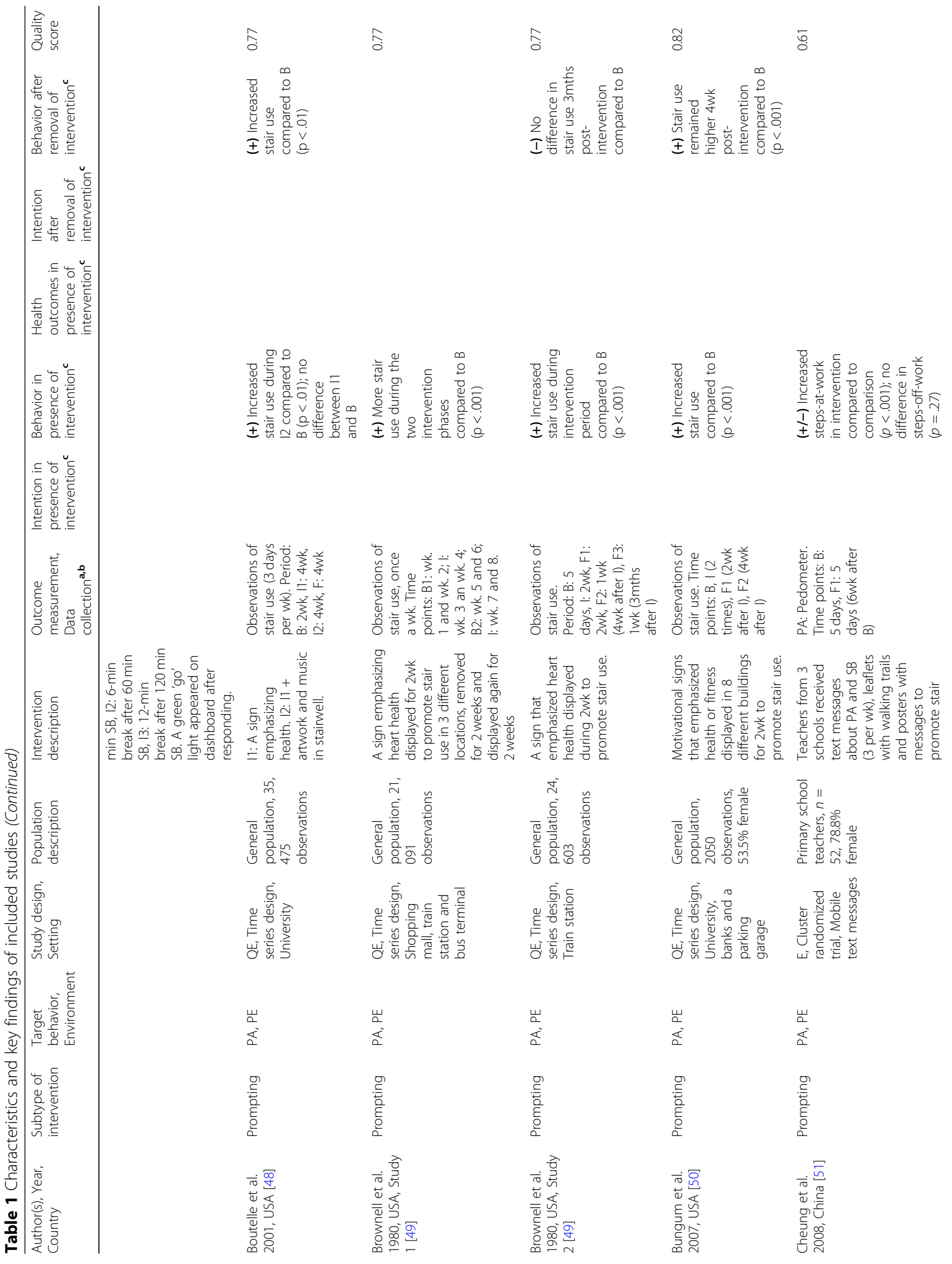




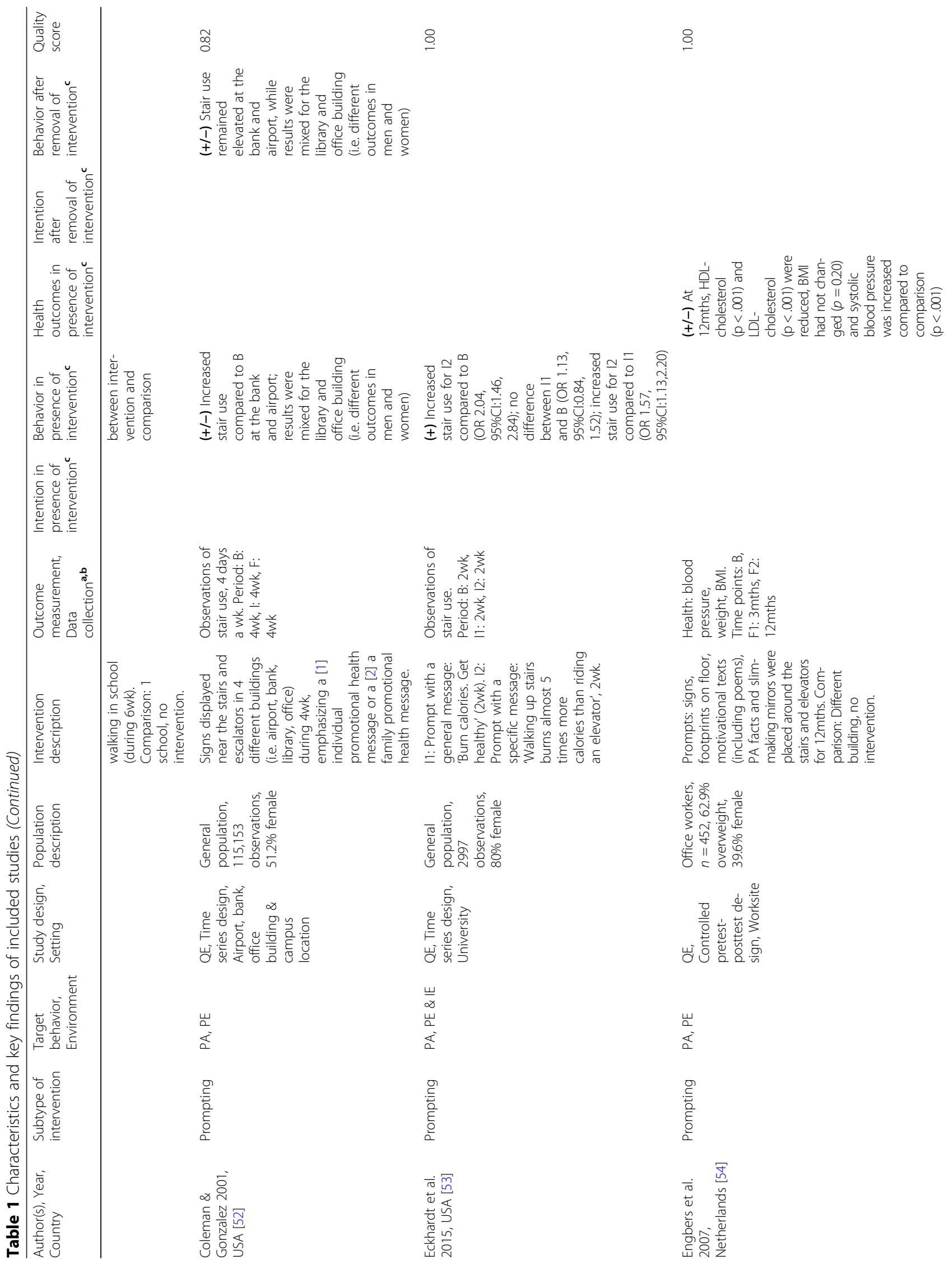




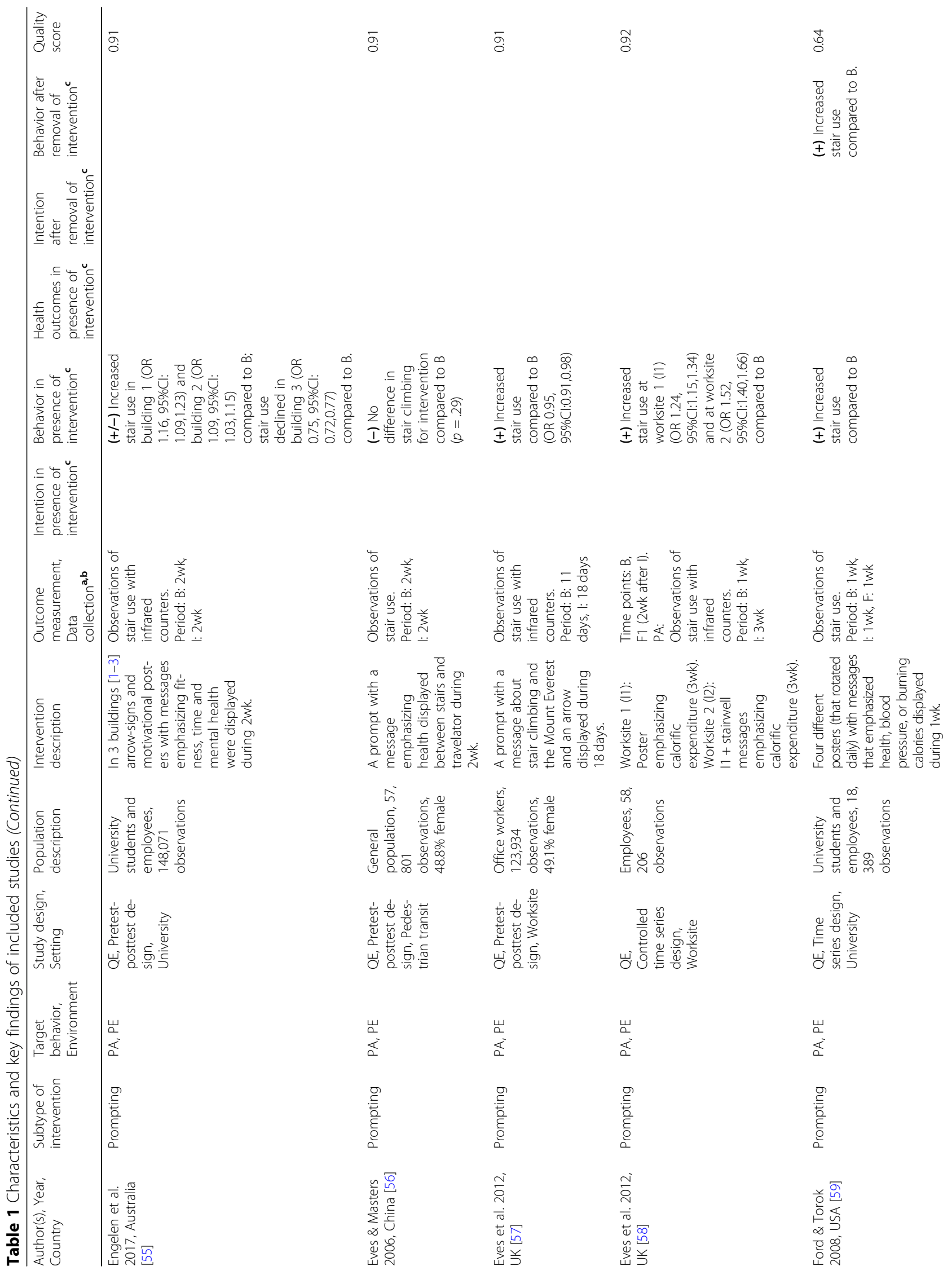




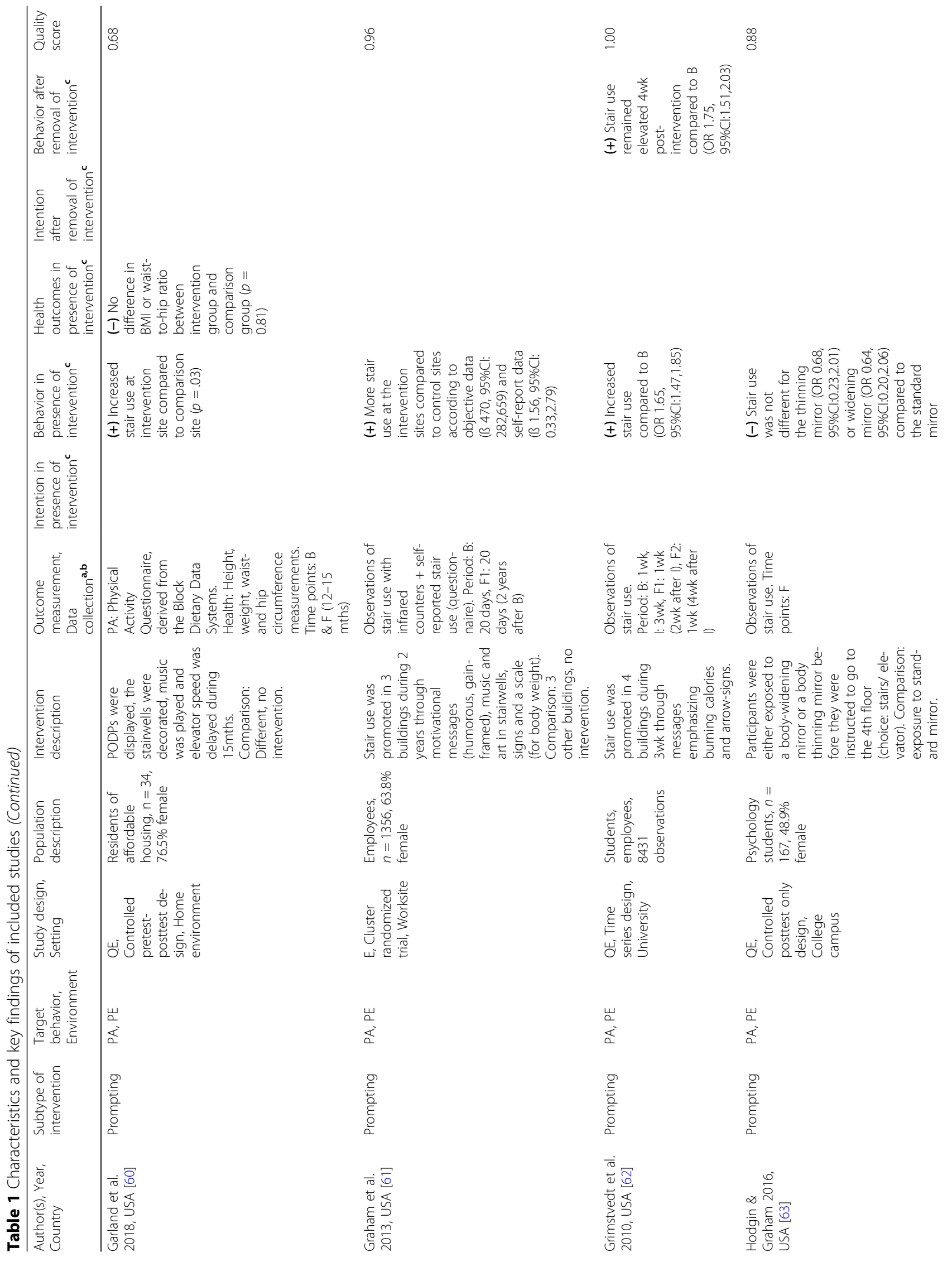




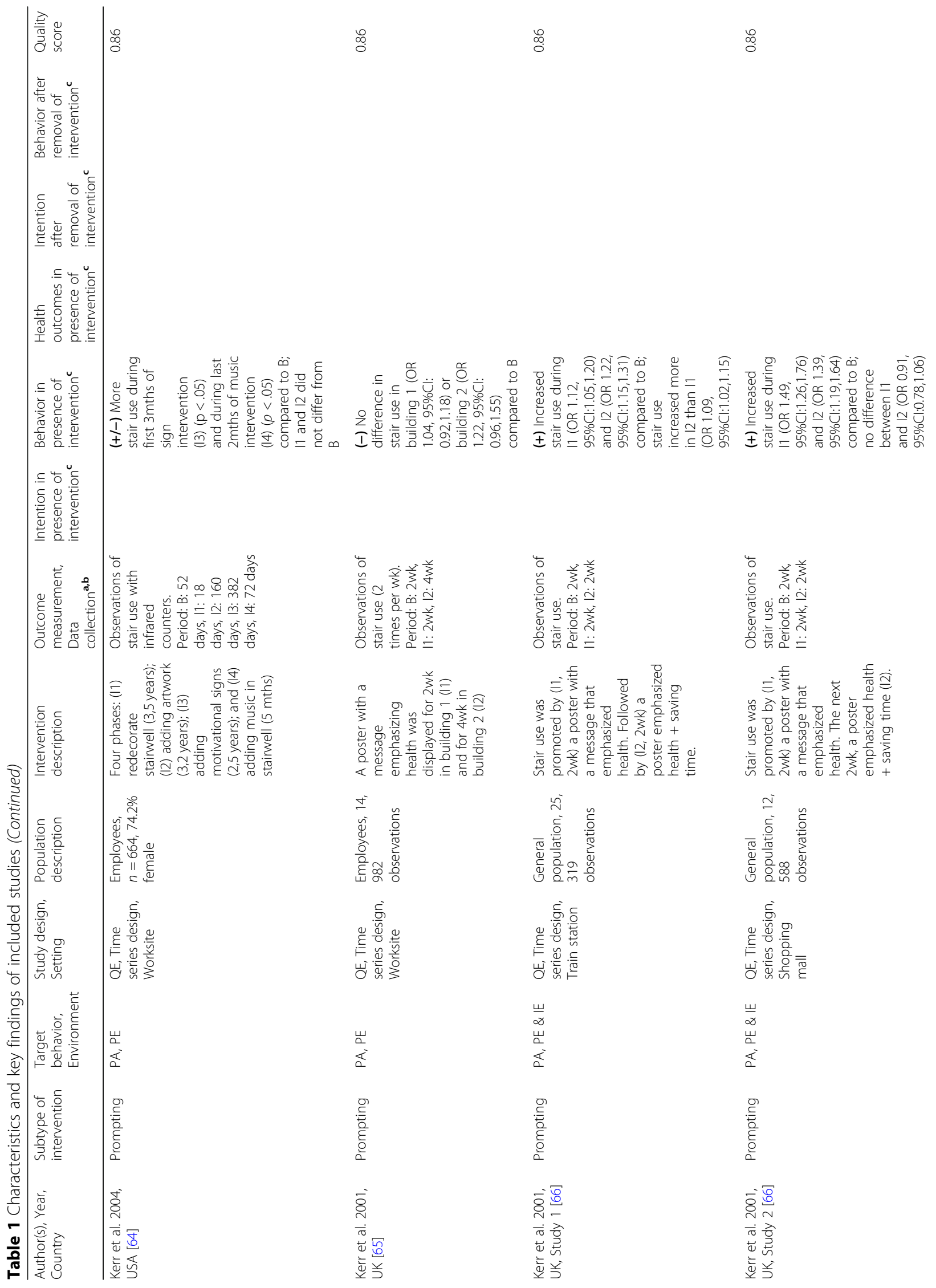




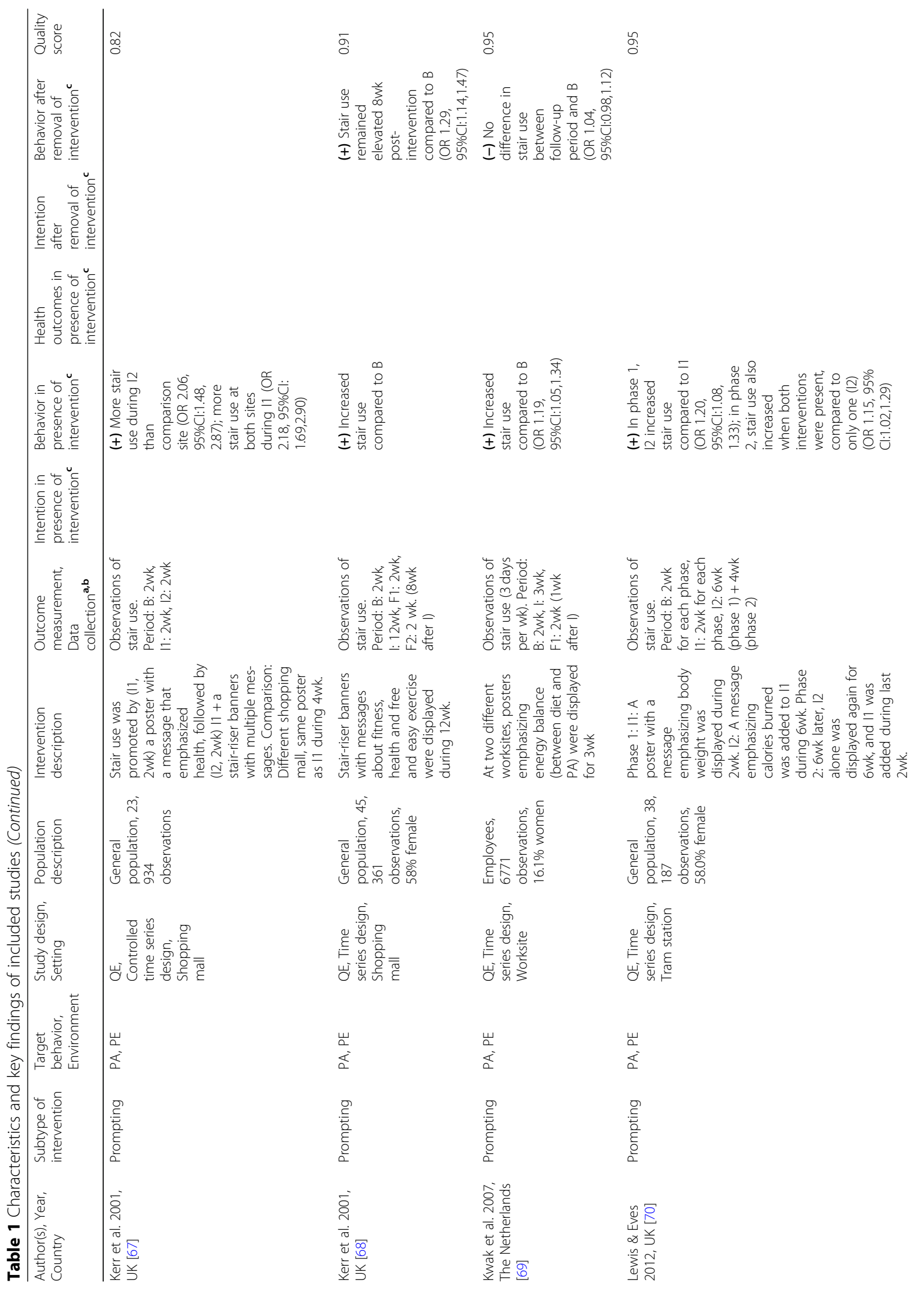




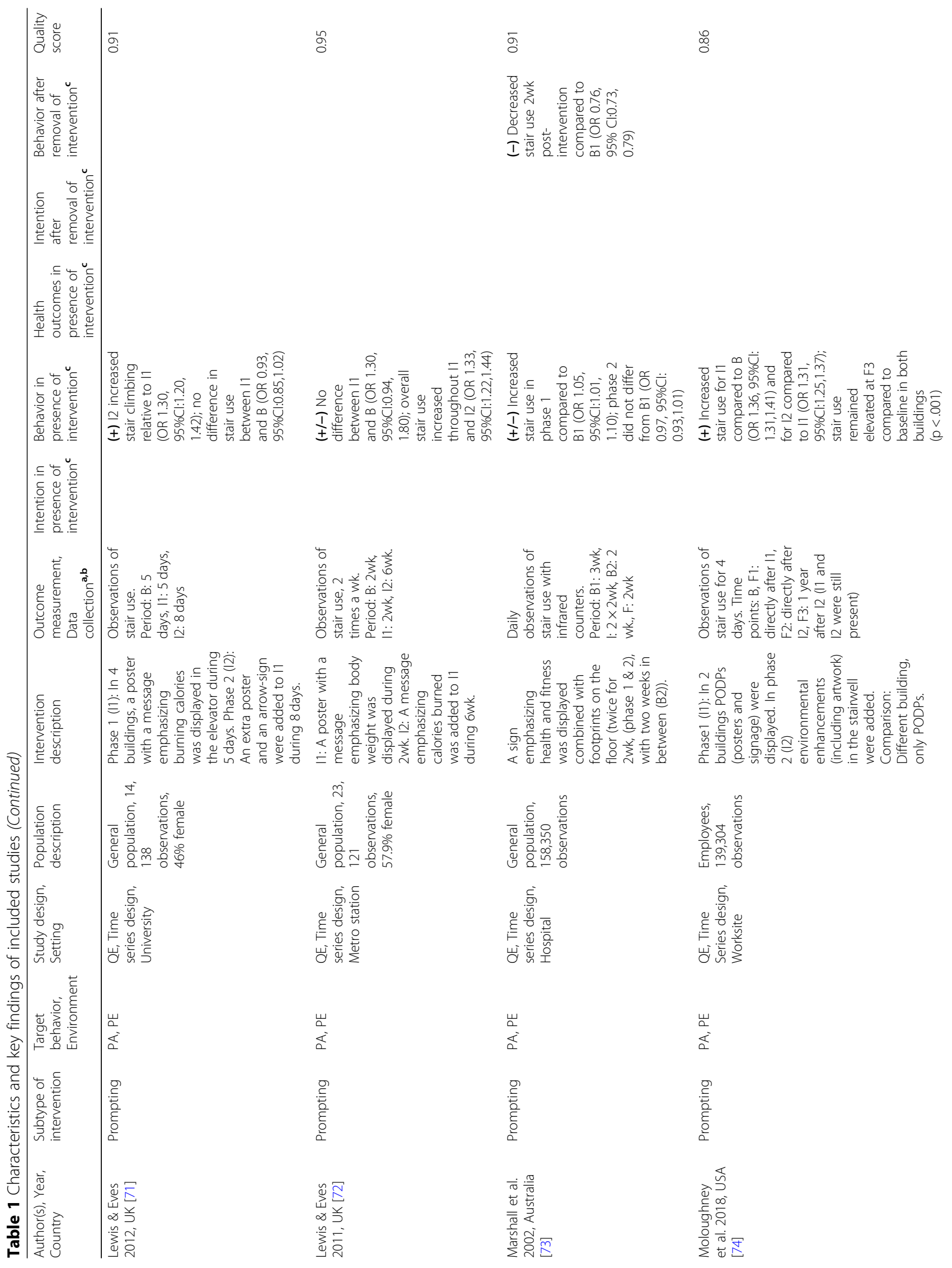




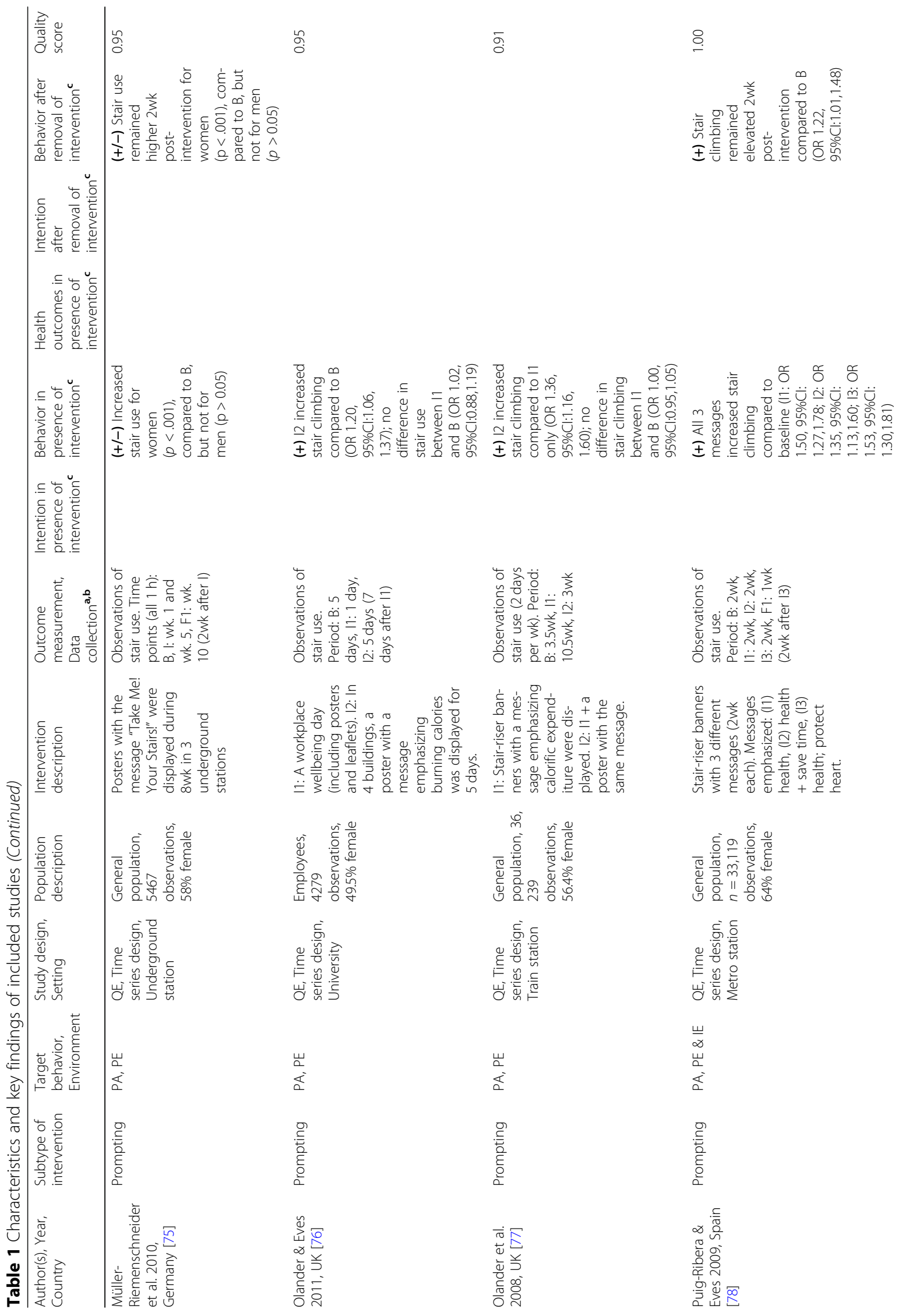




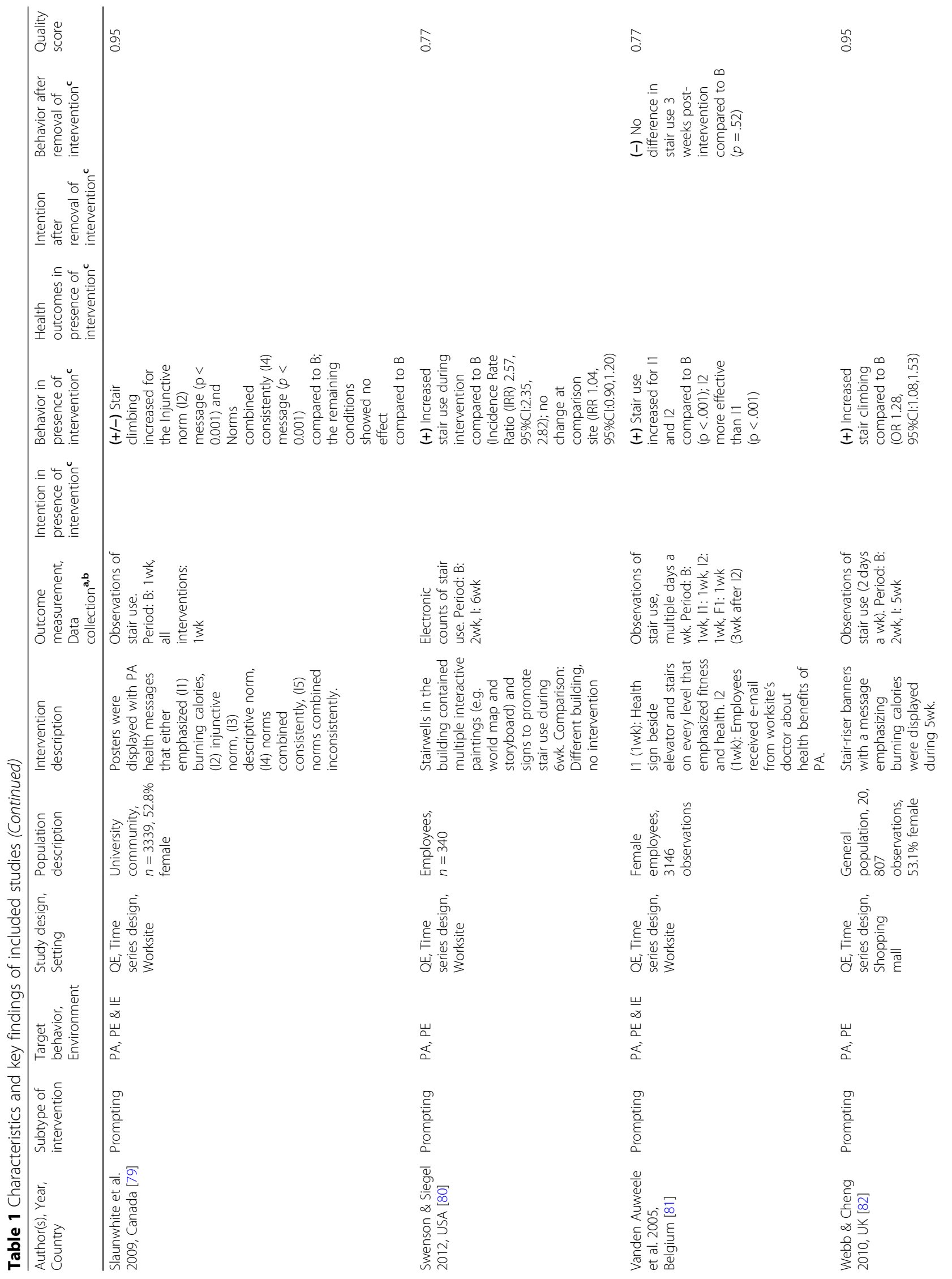




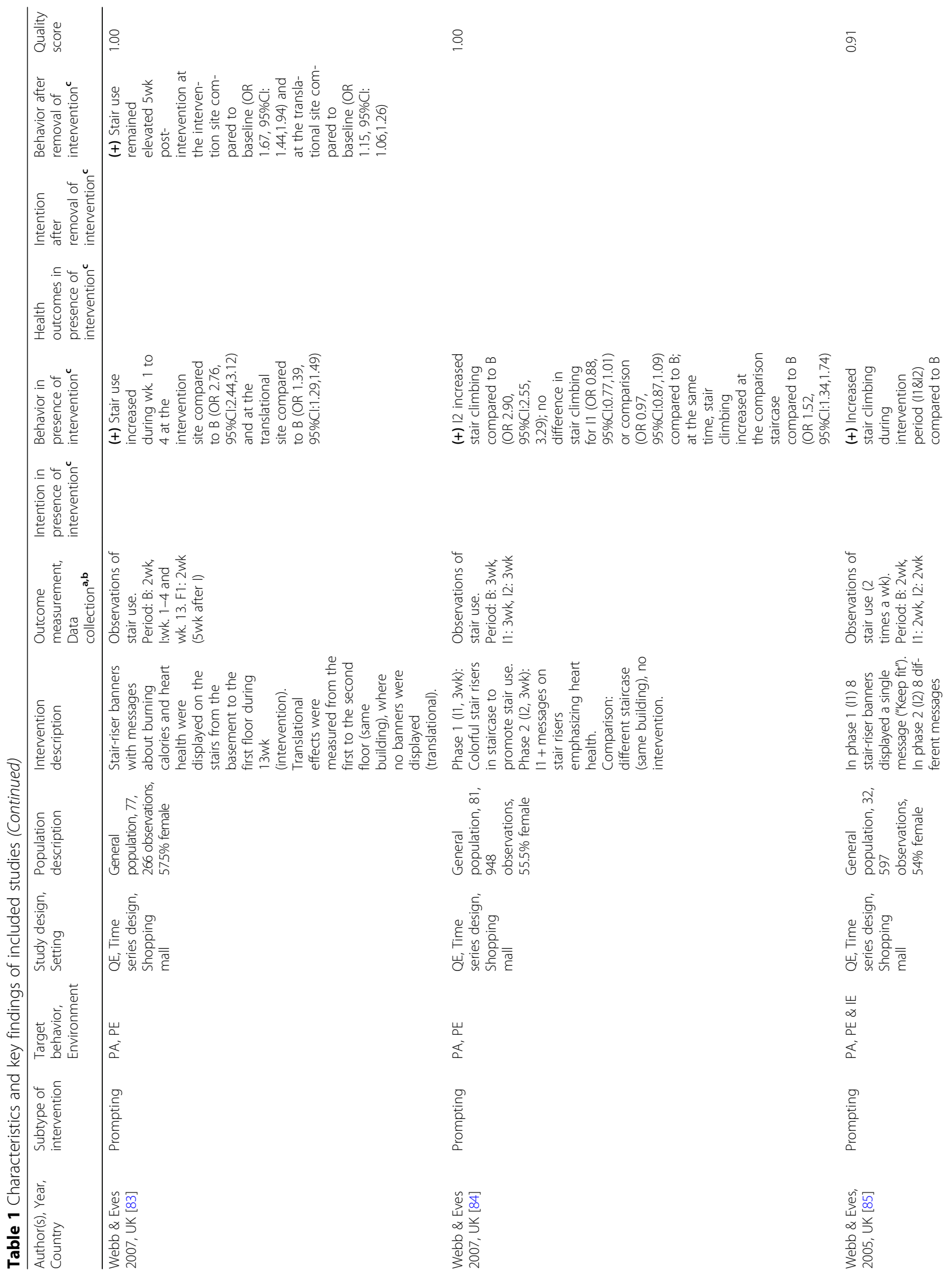




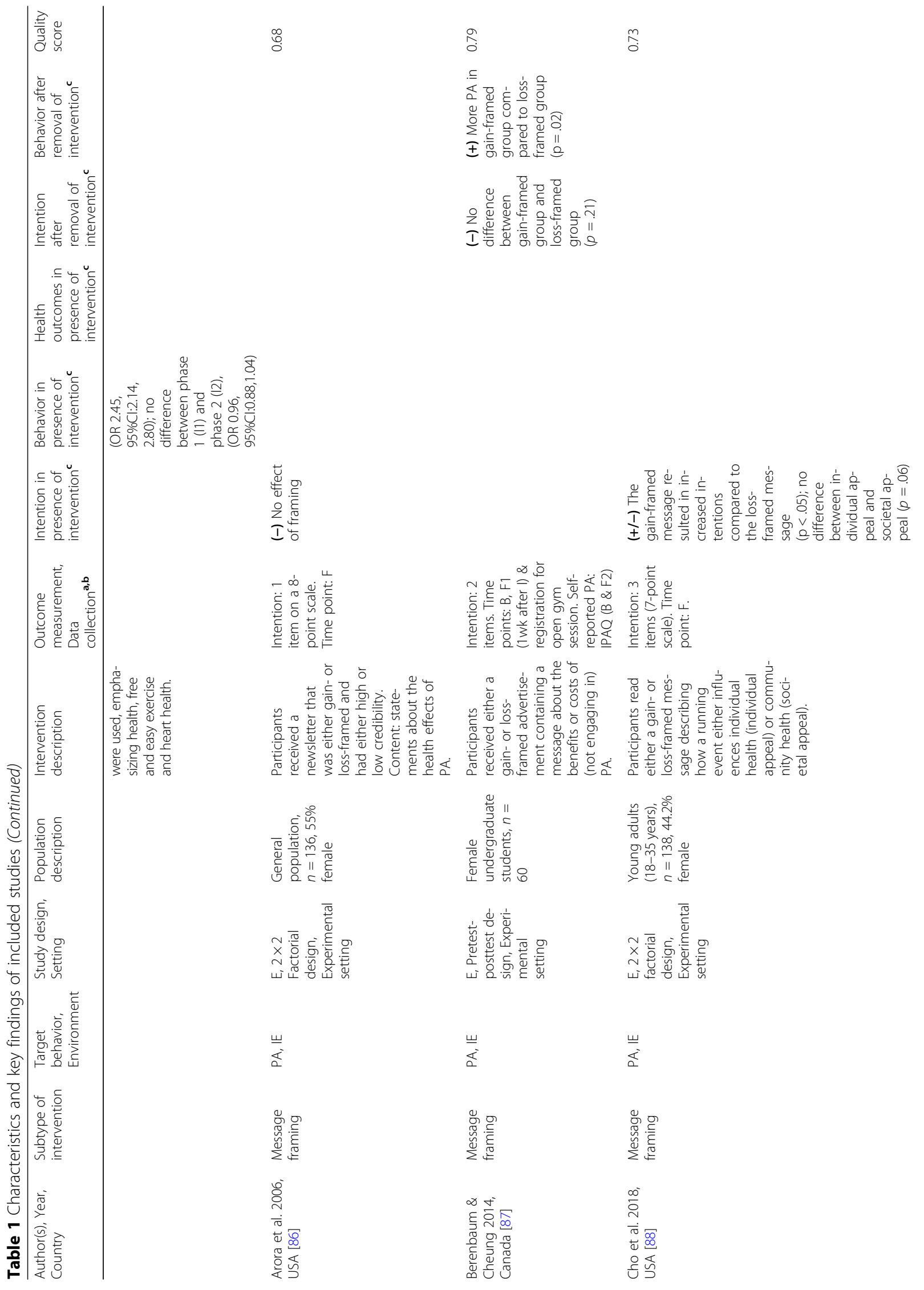




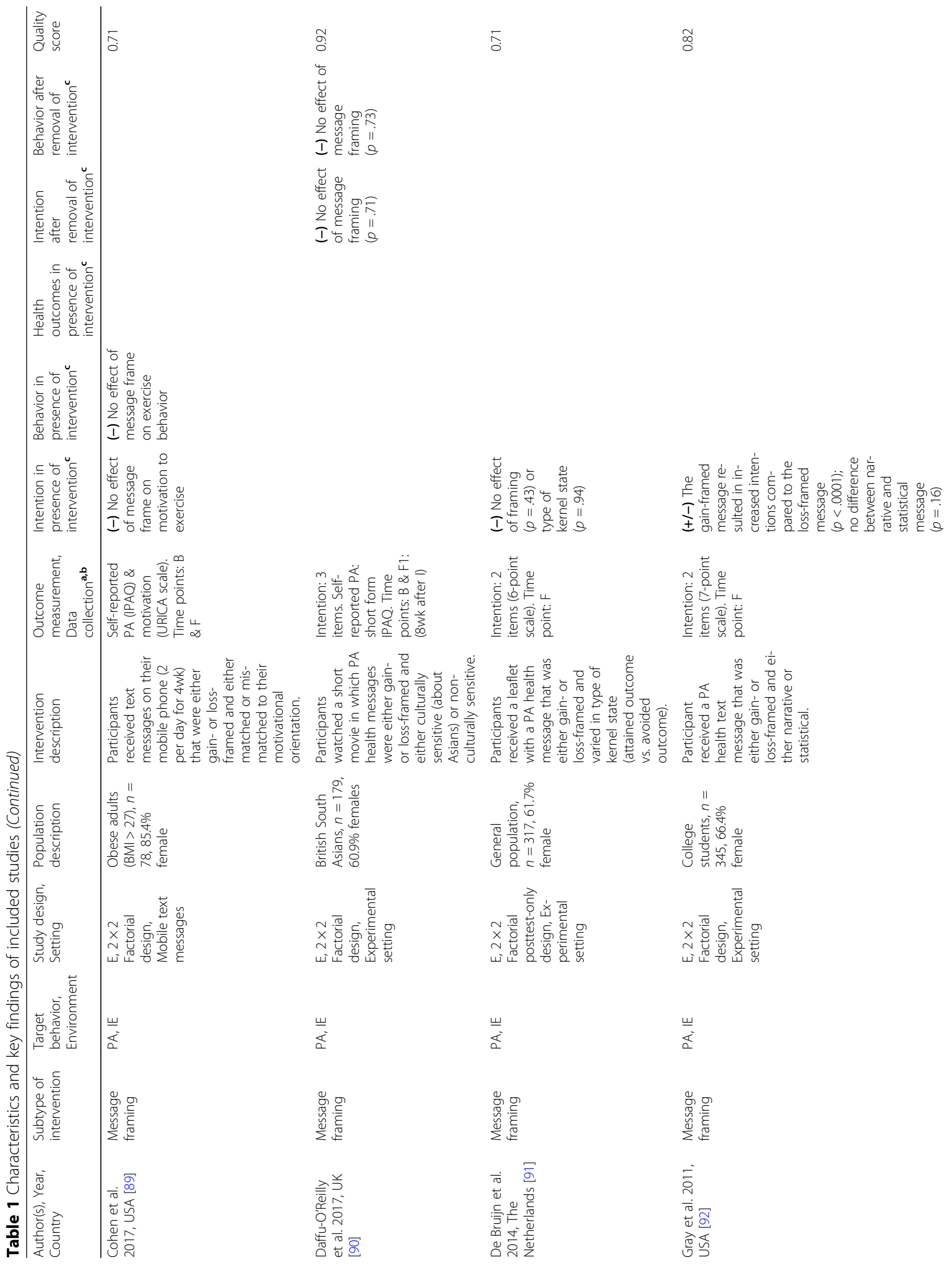




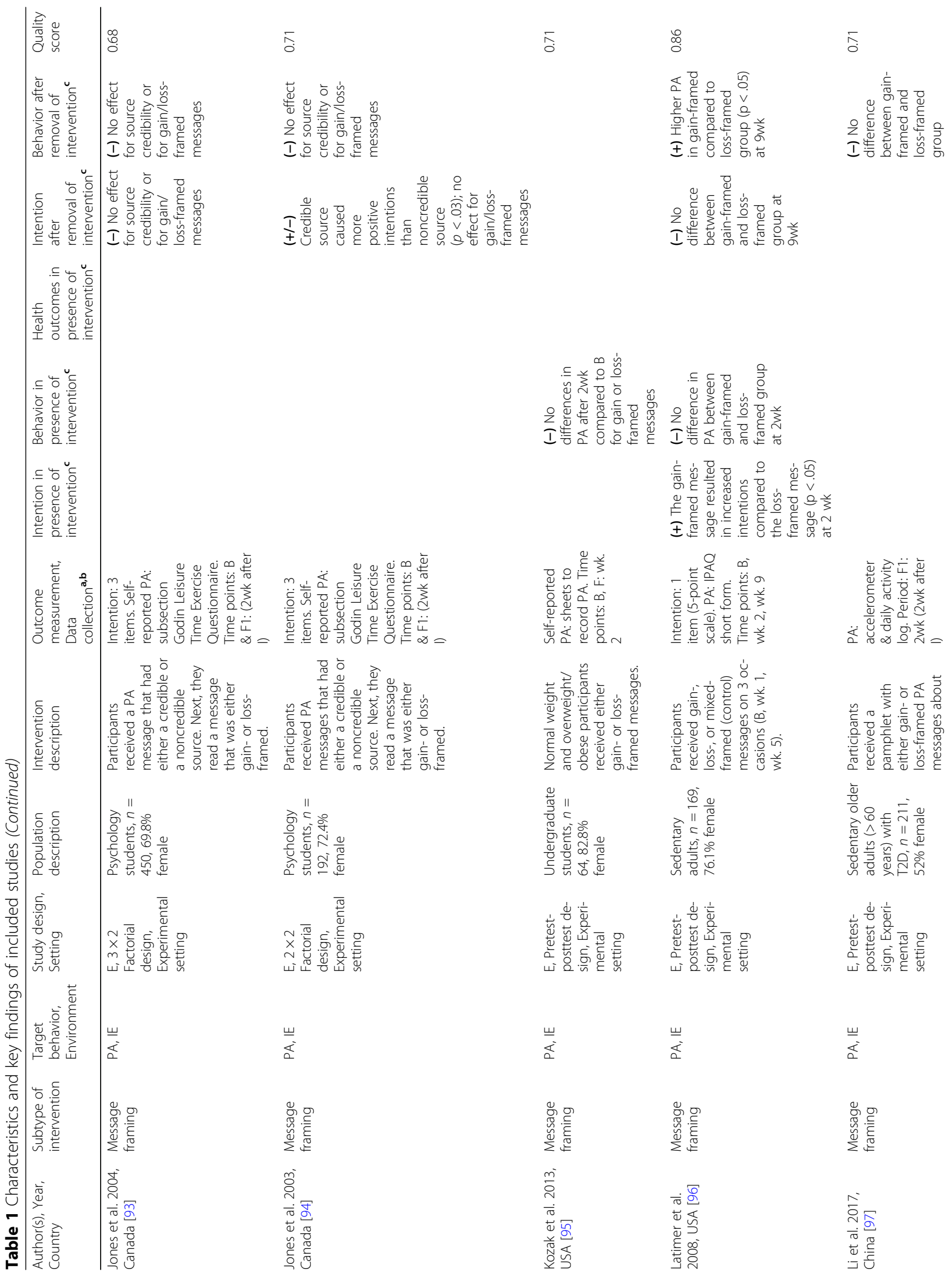




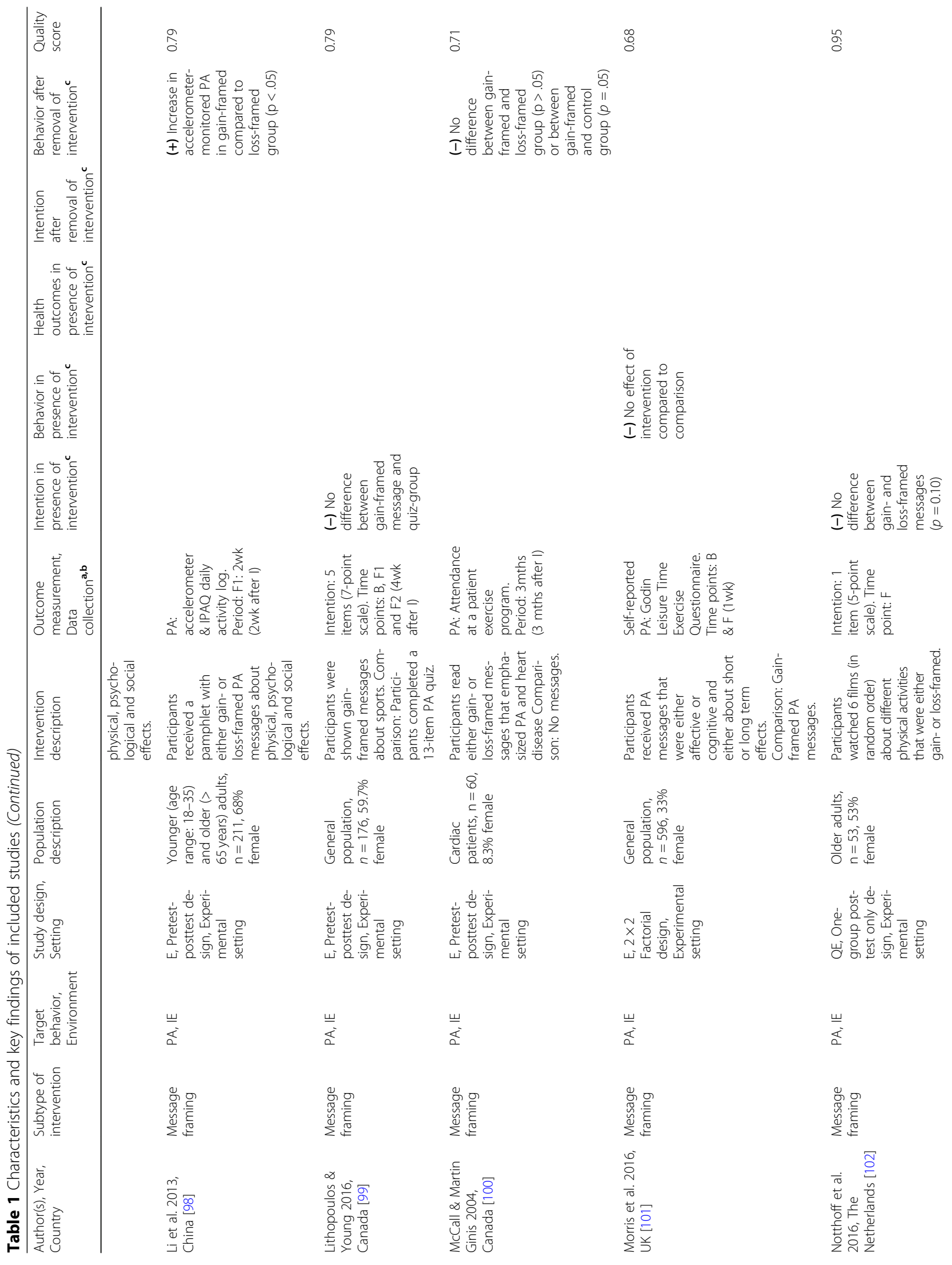




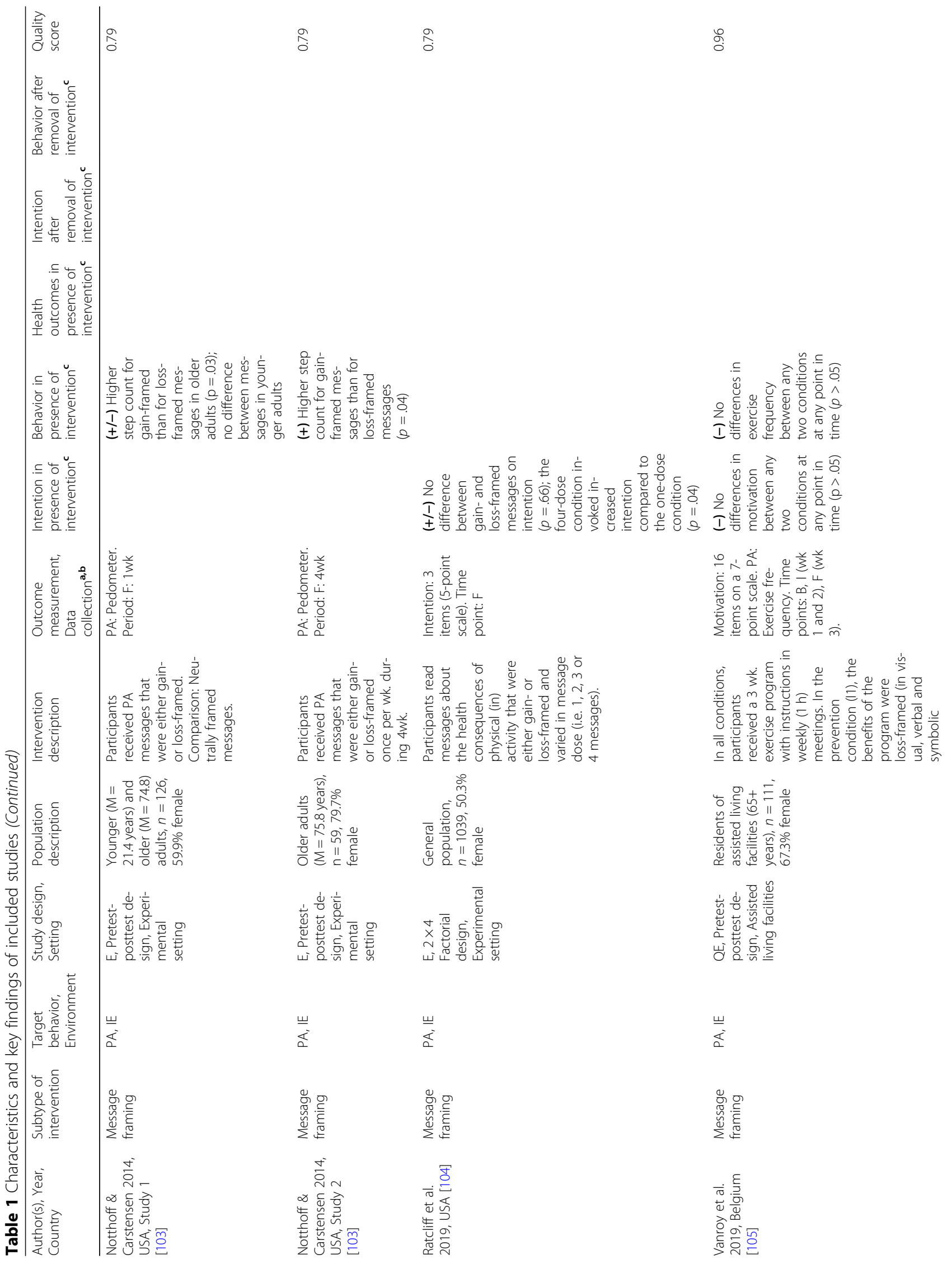




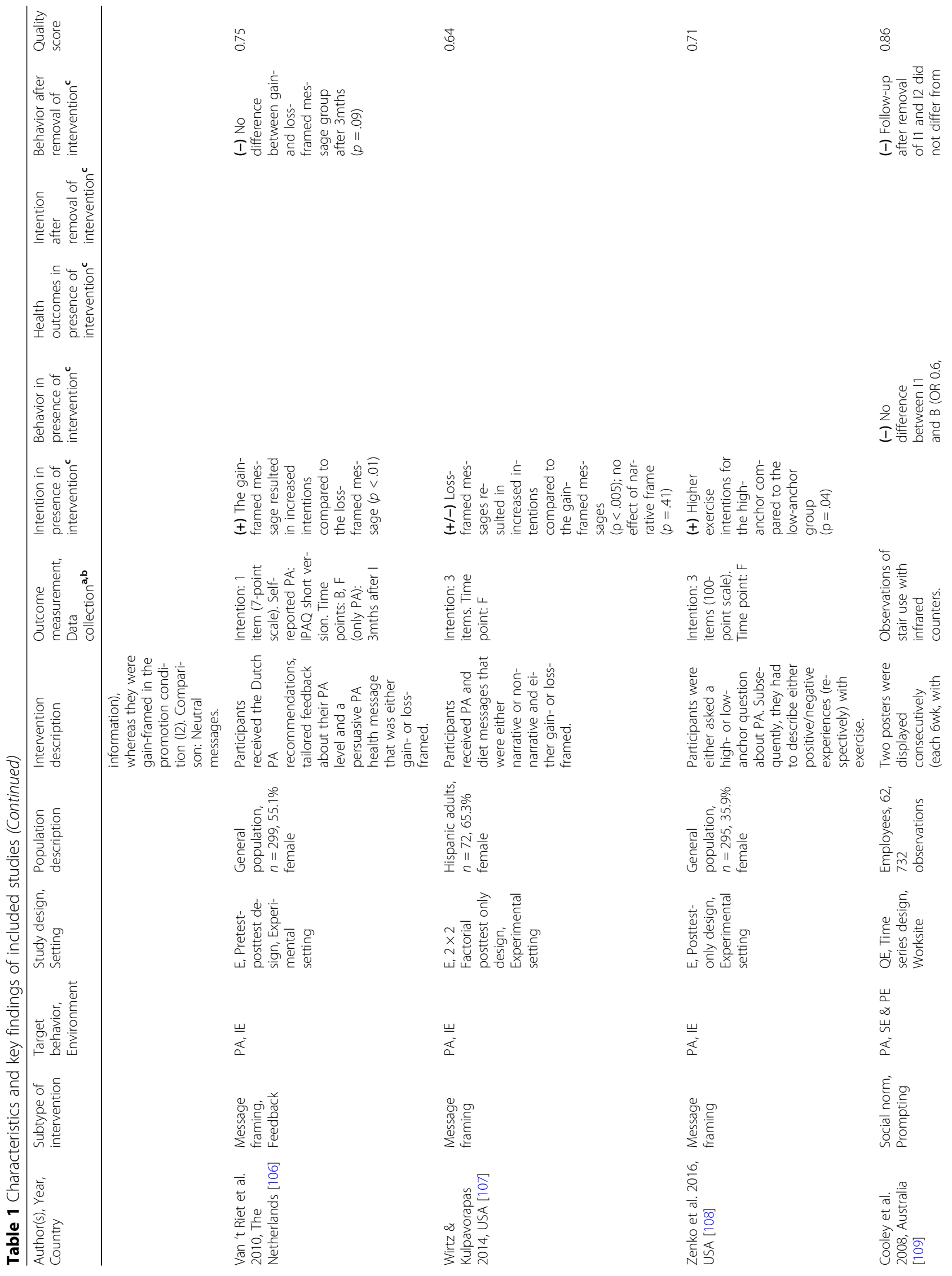




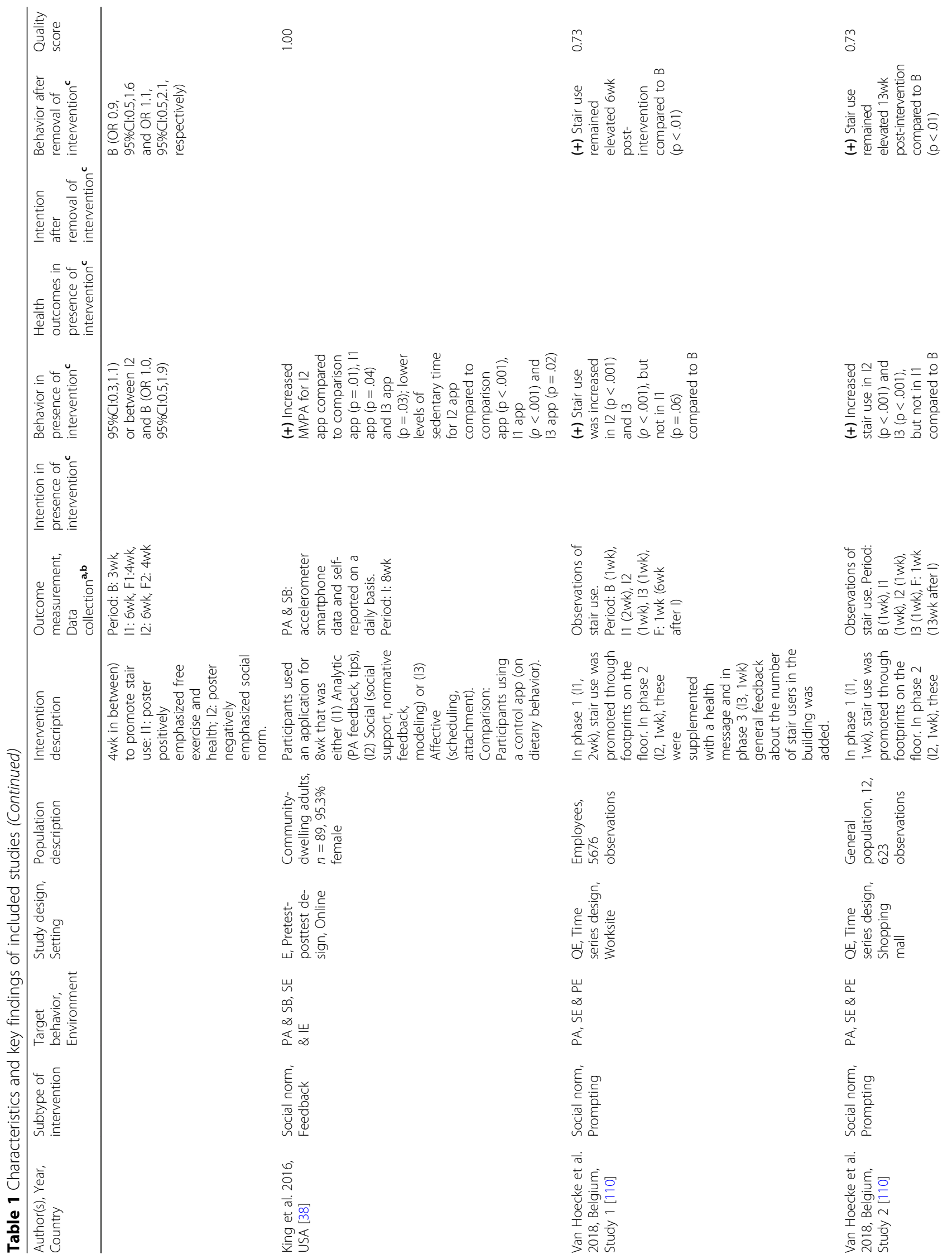




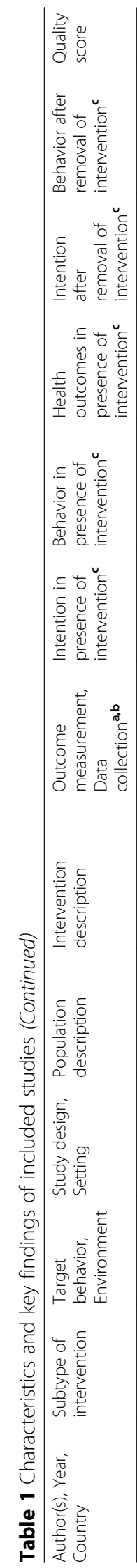

$\stackrel{\infty}{\infty}$

$\stackrel{\infty}{\infty}$

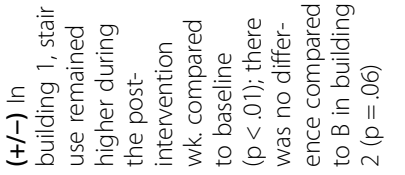

8

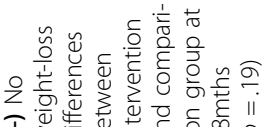

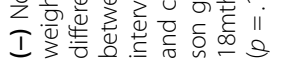

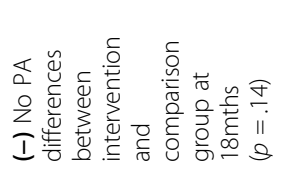

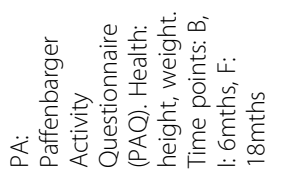

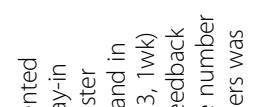

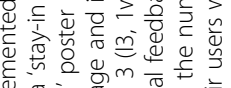

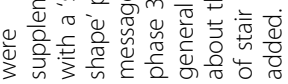

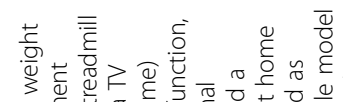

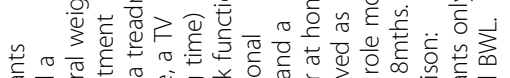

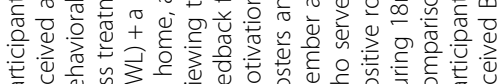

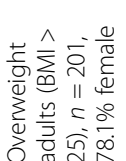

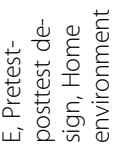

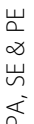

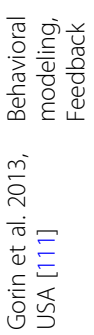

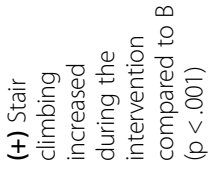

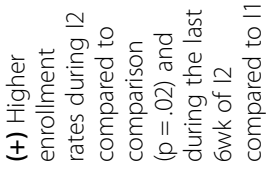

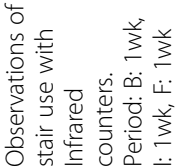

$\vec{i}$

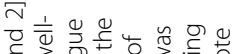

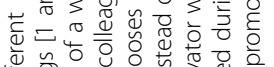

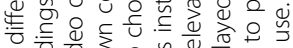

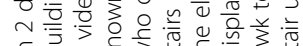

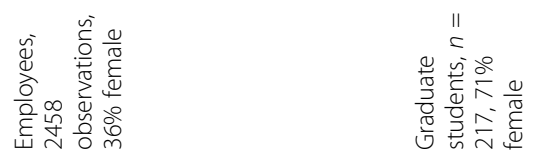

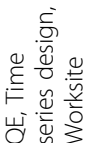

밍

㟧

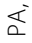

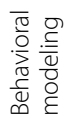

एँ

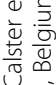

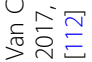

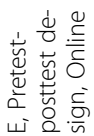

崩

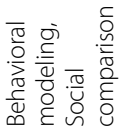

岪

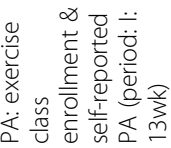

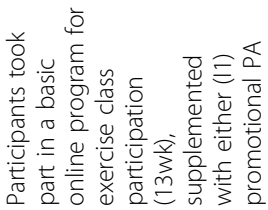

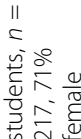

迹离

市 


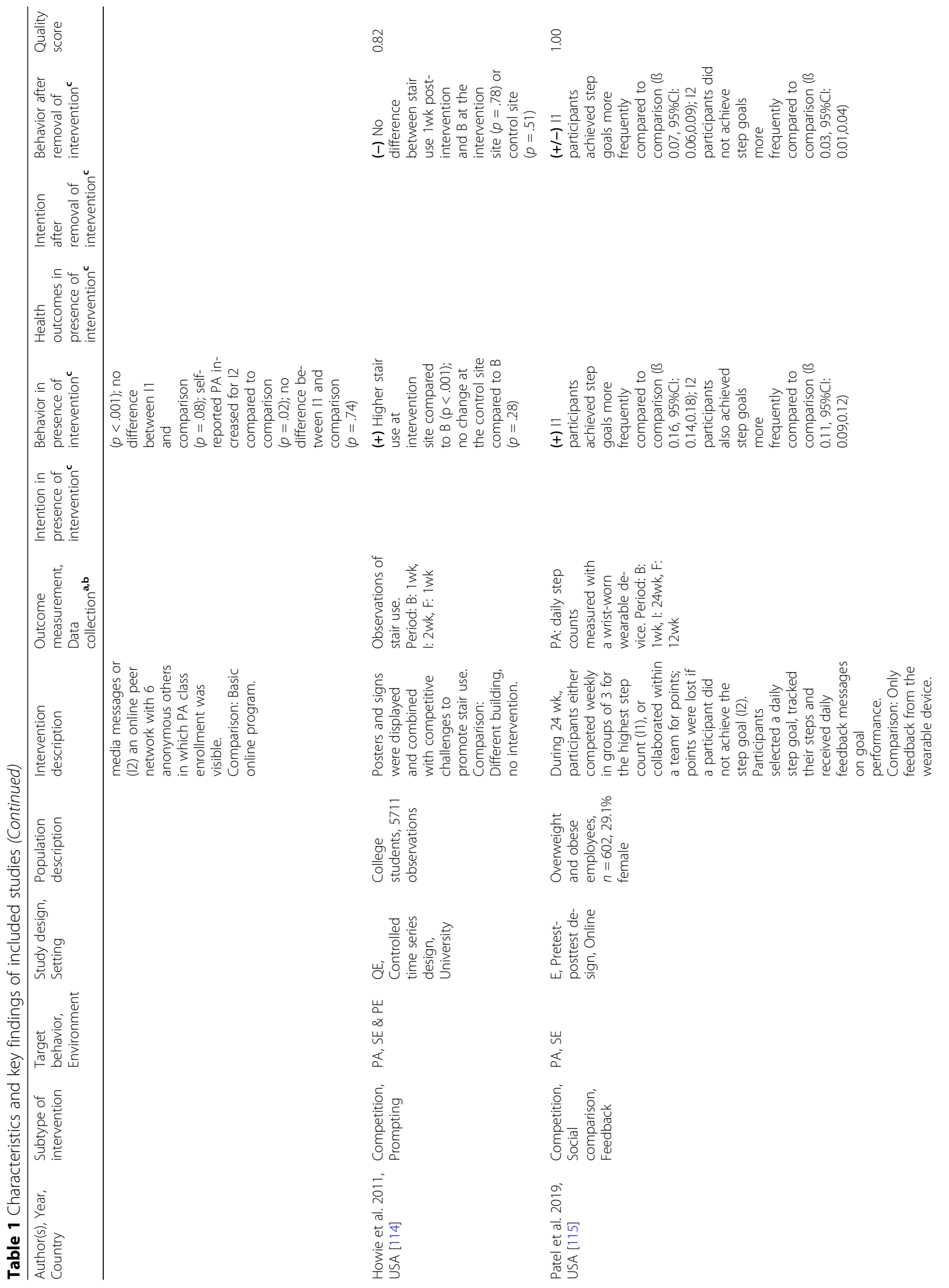




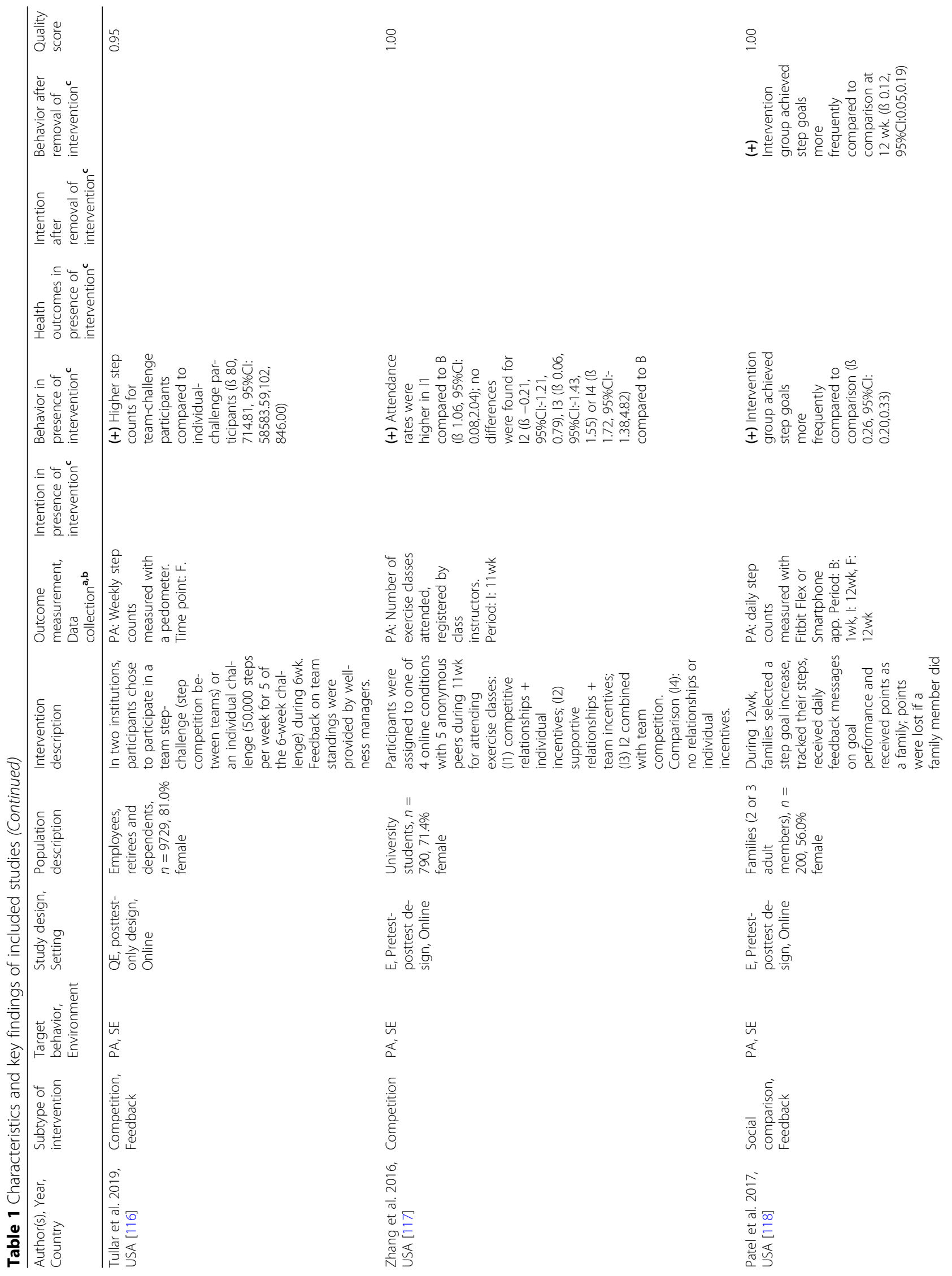




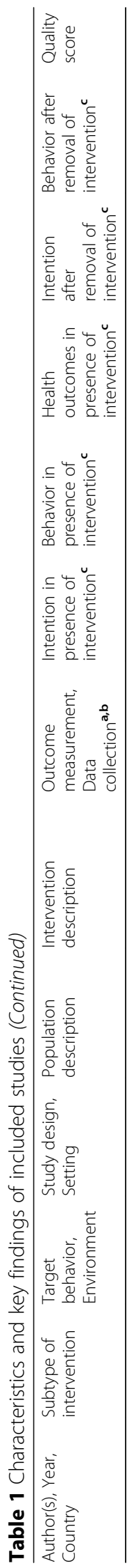

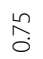

$\infty$

ڤ̆

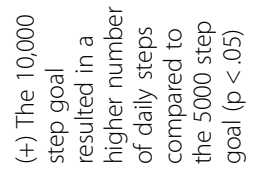

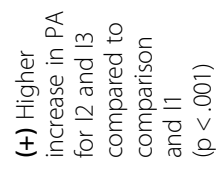

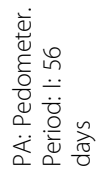

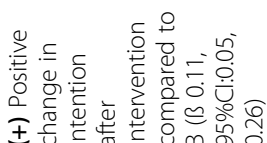

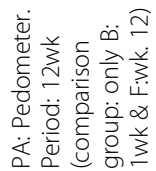

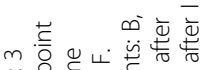

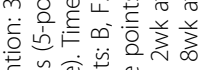

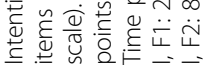

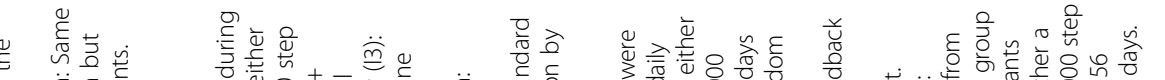

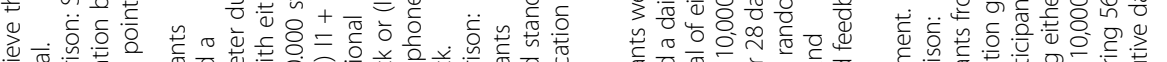

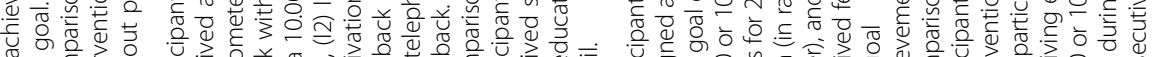

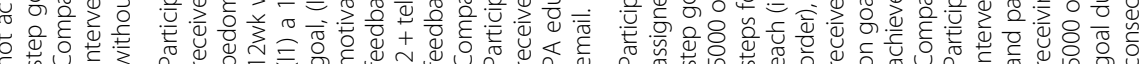

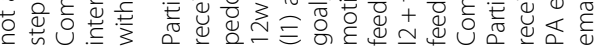

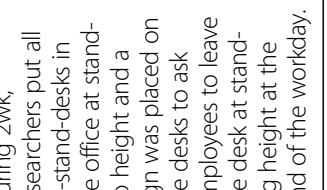

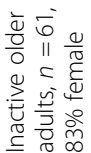

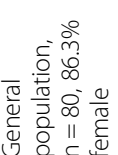

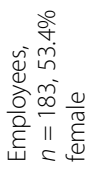

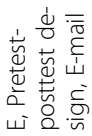

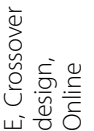

들

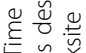

岁产产产

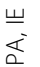

$\stackrel{\underline{m}}{\overleftarrow{\Sigma}}$

뜸

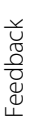

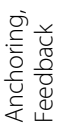

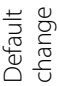

हें

त

윰

궁

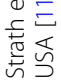

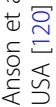

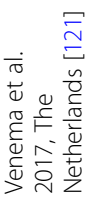




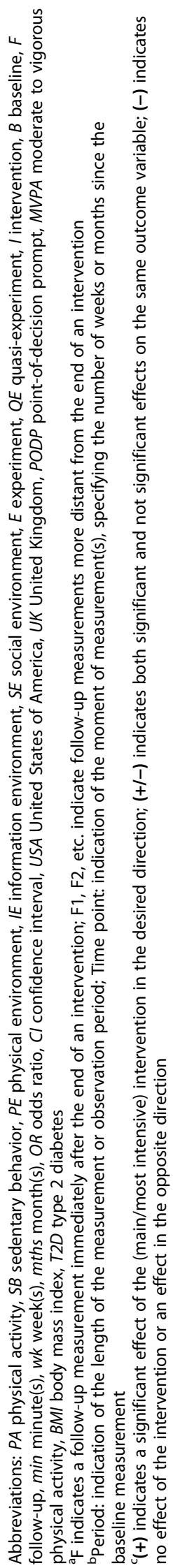


measuring devices $(n=11)$, including pedometers and accelerometers, validated questionnaires $(n=10)$, such as the International Physical Activity Questionnaire [123], and other self-report tools $(n=7)$, such as activity logs $[97,98,105]$. Studies that measured stair use $(n=48)$ counted the number of individuals that climbed the stairs within a certain time interval (mostly a few hours a day, during multiple weeks) by using observers $(n=36)$ or automatic (infrared) counters $(n=12)$. Three studies measured enrollment or attendance at exercise classes. Sedentary behavior was either assessed objectively [38, 47], for example by the SenseWear Mini Armband monitor [47], or observed by researchers [121]. Health outcomes were determined through biometric measurements, including body weight and blood pressure. The median duration of interventions was 21 days (range: 1 day to 24 months) and the median period between the end of an intervention and the most distant follow-up measurement 28 days (range: 1 day to 3 months).

\section{Quality of the included studies}

Table 1 presents the summarized quality scores for all studies. The majority of included studies $(n=70)$ were of high methodologic quality. The remaining studies $(n=18)$ were of moderate quality, with the lowest quality score being 0.61 [51]. Most of the moderate quality studies investigated the effectiveness of message framing. The relatively low quality score of these studies was mainly due to lack of blinding of investigators and participants or to lack of report on estimate of variance for the main results. A complete overview of quality ratings on all items can be found in Additional file 2 .

\section{Intervention effectiveness}

Effectiveness in presence of intervention versus after removal Overall, the effectiveness of interventions was more often measured in presence of the intervention $(n=80)$ than after removal of the intervention $(n=34)$. For intentions measured in presence of the intervention, four studies reported effective interventions $[96,106,108,121]$, four reported mixed effects $[88,92,104,107]$ and six reported no effect $[86,89,91,99,102,105]$. Among the relatively low number of studies $(n=5)$ that measured intention after removal of the intervention, one reported effectiveness [94], whereas four did not $[87,90,93,96]$.

For behavior, $67.6 \%$ of the interventions were effective $(38,40,41,43,45-49,52,56-61,65-70,73,75-84,102$, $109,110,112-120)^{1}, 13.2 \%$ showed mixed effects [51, $52,55,64,72,73,75,103]$ and $19.1 \%$ did not show an effect in presence of the intervention $[43,45,56,63,65$, $66,89,95,101,105,109,111]$. After removal of the intervention, $47.1 \%$ of the interventions showed a significant effect $(40,43,45,47,49,58,61,67,77,82,86,97$, $110,118)^{1}, 14.7 \%$ showed mixed effects $[39,52,75,112$,
$115]$ and $38.2 \%$ did not show an effect $[43,49,69,73$, 81, 90, 93, 94, 97, 100, 106, 109, 114]. An explorative analysis of characteristics of the studies that reported a significant effect after removal of the intervention revealed that on average, effective interventions lasted longer ( 7.3 weeks) than interventions that showed no effect (3.7 weeks). Message-framing studies were excluded from this explorative analysis, since these studies involved one-shot interventions.

Of the four studies that measured health outcomes in presence of choice architecture, one study [40] reported a significant effect on aerobic fitness, but not on other health outcomes; one study [54] reported a reduction in cholesterol levels, but no effect on BMI or blood pressure; and two studies $[60,111]$ reported no effect.

\section{Intervention techniques}

From the 88 included studies, we derived six different choice architecture intervention techniques, each of which is discussed below. Some intervention techniques were almost always applied in the physical-, social- and or information environment; in these cases, the corresponding environment is specified in parentheses.

\section{Prompting (physical and information environment)}

Fifty-three studies used prompting (38-84, 108, 110, $114)^{1}$, most importantly the use of point-of-choice prompts, such as posters, signs, stair-riser banners and directional footprints on the floor to promote stair use. Prompting interventions lasted between 1 day [41] and 3.5 years [64]. Among the 50 studies that looked into the effect of prompting on physical activity in presence of the intervention, $37(74.0 \%)$ reported a significant effect $(38,40,41,43,45,47-49,52,56-61,65-70,73,75-84$, $110,114)^{1}$, eight $(16.0 \%)$ reported mixed effects [51, 52, $55,64,72,73,75,79]$ and seven $(14.0 \%)$ reported no effect $[43,45,56,63,65,66,109]$. Twenty-one studies measured the effect of prompts on physical activity after removal of the intervention; twelve $(57.1 \%)$ reported a significant effect $(40,43,45,47,49,58,61,67,77,82,110)^{1}$, three $(14.3 \%)$ reported mixed effects $[39,52,75]$ and six (28.6\%) reported no effect [43, 49, 69, 73, 81, 114].

Prompts consisting of a message differed in the topic emphasized; most prompts emphasized the relationship between physical activity and health $(n=25)(38,41,44$, $45,47-49,51,54,55,58,64-68,72,77,80,82-84,108$, $110)^{1}$, caloric expenditure $(n=13)[44,53,58,59,62$, $70-72,76,77,79,82,83]$, physical fitness $(n=6)(49,54$, $67,72,80,110)^{1}$ or saving time $(n=6)(44,45,54,65$, $77)^{1}$. The messages showed significant effects on physical activity in $91.7 \%(11 / 12)$ of the studies that emphasized caloric expenditure $[44,53,58,59,62,70,71,76$, $77,82,83]$, in $72 \%(18 / 25)$ of the studies that emphasized the relationship between physical activity and 
health $(38,41,45,47-49,51,58,65-67,77,80,82-84$, $110)^{1}$, in $67 \%(4 / 6)$ of the studies that emphasized physical fitness $[50,68,81,110]$, and in $50 \%(3 / 6)$ of the studies that emphasized saving time [46, 66, 78]. In six studies, stair use was prompted by making the staircase more pleasant or attractive, for instance by decorating it with artwork and/or by playing music [48, 60, 61, 64, 74, 80]. Five out of these six studies $(83.3 \%)$ reported a significant effect on physical activity $[48,60,61,74,80]$, although it should be noted that some interventions were combined with other choice architecture intervention components. Two studies prompted physical activity through e-mail or mobile phone messages that emphasized the health benefits of physical activity; one reported effectiveness [81] and one mixed effectiveness [51]. One study showed significantly reduced sedentary behavior by prompting physical activity breaks through mobile phone messages [47].

\section{Message framing (information environment)}

Twenty-four studies compared the effect of a message framed in a certain way with a similar message framed in a different way on individuals' physical activity intentions and/or behaviors $(85-107)^{1}$. The majority of these studies compared gain-framed messages with lossframed messages $(n=21)$.

Out of the eleven studies $[86,88,89,91,92,96,102$, 104-107] that measured physical activity intentions in presence of the intervention, five $(45.5 \%)[88,92,96$, $106,107]$ showed that gain-framed messages were more effective than loss-framed messages. However, two of these studies showing effectiveness was of moderate quality $[88,107]$. Among the six studies $(88,94,95,102$, $104)^{1}$ that measured physical activity behavior in presence of the intervention, one study (16.7\%) [103] demonstrated that gain-framed messages were more effective in changing physical activity.

After removal of the intervention, five studies [87, 90, 93, 94, 96] measured the effect of gain- versus lossframed messages on intentions and nine studies [87, 90, 93, 94, 96-98, 100, 106] on behavior; none of those studies reported a difference between the effect of gain- and loss-framed messages on intentions and in three of those studies [87, 96, 98], gain-framed messages caused a higher increase in physical activity compared to lossframed messages.

Other types of framing included for example a credible versus non-credible source message $(n=2)$ [93, 94] or a narrative versus non-narrative message $(\mathrm{n}=$ 2) [92, 107]. Among these studies, one [94] reported a significant difference between messages: the credible source resulted in higher exercise intentions than the non-credible source.

\section{Social influence (social environment)}

Twelve studies used social influence interventions (108$118)^{1}$, including descriptive social norms $(n=4)(108-$ $110)^{1}$, behavioral modeling $(n=3)$ [111-113], encouragement of competition between individuals or teams $(\mathrm{n}=4)$ [114-117], and facilitation of social comparison through information about the performance of others $(\mathrm{n}=3)[113,115,118]$. All studies providing a descriptive social norm (i.e. messages that specify the prevalence of a specific behavior), except one [109], reported a significant effect on behavior in presence of the intervention. One study found a significant increase in physical activity, as well as a significant decrease in sedentary behavior [38]. Three studies using descriptive social norms also measured physical activity after removal of the intervention $(108,110)^{1}$. Among these, two studies $(110)^{1}$ reported effectiveness; however, both studies were of moderate quality.

Within the three studies in which behavioral modeling was applied (i.e. demonstration of the desired behavior by another person), two studies (66.7\%) [112, 113] reported a significant increase in physical activity in presence of the intervention, whereas one did not [111]. One study also measured the effectiveness after removal of the intervention and reported mixed effects: stair use only remained elevated after removal of the intervention in one of the two intervention buildings [112].

The four interventions that encouraged competition all effectively increased physical activity in presence of the intervention. For two of the interventions, effects were also measured after removal of the intervention $[114,115]$; these effects were significant in one study [115]. Finally, the three studies that provided information about physical activity performances of others all reported a significant effect on physical activity during the intervention. Measures after removal of the intervention were performed in two of these studies $[115,118]$; the effect was significant in one study [118].

\section{Feedback}

Feedback was used as an intervention technique in eight studies [38, 47, 106, 115, 116, 118-120]. These interventions consisted of behavioral feedback on one's level or performance of physical activity $[38,106,115,116,118-$ 120], or on time spent in sedentary behavior [47]; all reported a significant effect on behavior in presence of the intervention. Three studies also measured the effectiveness after removal of the intervention [106, 115, 118]; one study [118] found a significant increase in physical activity and one study found a significant increase in physical activity for one condition, but not for another condition [115]. 


\section{Default change}

One study changed the default (i.e. a sit-stand desk was placed at stand-up height instead of sitting height) to encourage sedentary office workers to use the desk in a standing position [121]. The results showed that the intention for stand-up working significantly increased from pre- to post-measure.

\section{Anchoring}

One study used anchoring to increase daily steps - participants were either assigned a 5000 step goal (low anchor), or a 10,000 step goal (high anchor) - and reported that the high anchor condition resulted in a significantly higher number of daily steps compared to the low anchor condition [120].

\section{Discussion}

\section{Summary of evidence}

The aim of this systematic review was to summarize studies on micro-environmental choice architecture interventions that encourage physical activity or discourage sedentary behavior in adults, and to describe the effectiveness of those interventions on these behaviors and on related intentions or health outcomes - in presence of the intervention and after removal of the intervention. Within the 88 included studies, six broad choice architecture intervention techniques were distinguished, including - in order of decreasing frequency prompting, message framing, social influence, feedback, default change and anchoring. In the physical environment, we encountered mostly prompting interventions; in the social environment mostly social influence interventions and in the information environment mostly message framing studies. A great majority of studies targeted physical activity, predominantly stair use, while only three studies focused on reducing sedentary behavior. The results of the review suggest that choice architecture interventions effectively encourage stair use in adults, especially in presence of the intervention. However, since we did not assess effect sizes and only few studies reported follow-up outcomes, it remains unclear how meaningful these increases in stair use are on an individual level.

Consistent with previous research on health behavior change interventions in general [9], a higher proportion of studies reported a significant effect on behavior in presence of the intervention compared to after removal of the intervention. The presence of an intervention likely disrupted habitual behavior [124] (e.g. elevator use) and motivated the choice for a different, healthier option (e.g. the stairs) by bringing existing beliefs (such as 'taking the stairs is good for my health') into consciousness, while removal of the intervention probably decreased the salience of beliefs about the healthy option
[69]. According to Wood \& Neal (2016), behavior change interventions of longer duration tend to be more successful, because they allow for formation of new habits [9]. Indeed, the results of the current review demonstrate that interventions that had lasted longer were most successful in maintaining increases in physical activity after removal of the intervention. This finding should, however, be interpreted with caution since we did not control for other factors (e.g. moment of followup measurement). Those findings raise the question: how long should choice architecture interventions generally take to promote habit formation? A study by Kaushal et al. (2015) demonstrated that individuals needed at least six weeks of regular gym workouts to establish new exercise habits [125]; according to a study by Lally et al. (2010), the duration of habit formation varies highly between individuals, ranging from 18 to 254 days [126]. A potential disadvantage of a choice architecture intervention of longer duration in the physical environment could be that individuals become accustomed to it and therefore no longer notice it [39].

A relatively high number of studies that examined social influence as choice architecture technique reported significant changes in behavior, especially in presence of the intervention; eight out of ten studies increased physical activity and the only study that targeted sedentary behavior reported a decrease in sedentary behavior. The descriptive social norm interventions may be effective because people generally fear ostracism and experience a robust need to belong, which drives them to behave appropriately and receive approval $[127,128]$. Evidence for the effectiveness of social norm interventions has also been demonstrated in other domains, such as alcohol consumption among college students (e.g. [129]). Due to the limited number of social influence studies identified in the current review, we cannot draw conclusions regarding the most effective type of social influence intervention.

With regard to message framing, our review predominantly identified studies that compared gain-framed messages with loss-framed messages. It should be noted that comparisons between message framing conditions differ from the comparisons that were made in most of the other studies included in this review; in the latter, intervention effects were often compared with 'no intervention'. As opposed to Gallagher and Updegraff (2012) [24], who reported in their meta-analytic review that gain-framed messages more effectively promoted prevention behaviors (including physical activity) compared to loss-framed messages, we found no favorable effect of gain-framed messages over loss-framed messages on physical activity. This inconsistency in findings can be explained by the fact that more recently published message framing studies were included in our study (i.e. [89, 
$90,95,97,101])$, of which the majority did not report a significant effect on physical activity. For intentions to engage in physical activity, the findings of our review did not show a favorable effect of gain-framed over lossframed messages either.

It is hard to assess the effectiveness of studies that investigated feedback, default change or anchoring as choice architecture technique, because those studies were underrepresented. Moreover, most of the studies that contained feedback also contained another choice architecture technique, which hampered assessment of the effectiveness of feedback alone. Studies on sedentary behavior were underrepresented as well. This can be explained by the fact that, contrary to physical inactivity, the adverse effects of excessive sedentary behavior on health have been fully recognized relatively recently $[4,130]$.

It must be noted that the choice architecture intervention techniques reviewed are not necessarily new compared to the behavior change techniques (BCTs) described in previous taxonomies of choice architecture and taxonomies of BCTs more in general. For example, some BCTs from the Behavior Change Taxonomy from Michie et al. (2013) (e.g. 'Restructuring the physical environment' and 'Restructuring the social environment') cover choice architecture techniques that were identified by the current review [131]. In our review, we used terms for choice architecture techniques as they are commonly used in the choice architecture literature (e.g. 'default change' and 'anchoring'), because those terms refer to more specific techniques than the techniques from the taxonomy from Michie et al. [10, 12]. In addition to choice architecture techniques, a wide variety of other BCTs exists [131], such as social support or punishment, but our review did not look at combinations of choice architecture and such other BCTs. Since we excluded multicomponent interventions, we cannot assess whether choice architecture techniques alone, or combined with other BCTs, more effectively change physical activity and sedentary behavior. However, the exclusive focus of our review on choice architecture interventions permits attribution of the effects to specifically those interventions.

\section{Strengths and limitations}

Important strengths of our review are the addition of backward and forward citation searches to the database searches and the assessments of study quality by two independent reviewers. This review also contains several limitations. Firstly, accurate assessment of intervention effectiveness was impeded by the fact that (a) few studies adopted a controlled experimental research design; (b) few studies used objective measurement tools; and (c) we reported the effects of interventions in terms of statistical significance - which is less informative than assessment of effect sizes. Moreover, maintenance of behavior change is hard to assess based on this review, due to the often short-term nature of follow-up measures, and the fact that we reported outcomes in terms of 'presence or absence of the intervention', without taking the elapsed time at follow-up into account. High heterogeneity between studies in regard to study design, intervention characteristics, type of outcome measure and outcome measure assessment prevented us from conducting a meta-analysis; therefore, we were limited in comparing the effectiveness of interventions between studies. Since the vast majority of studies measured only stair use, the results cannot be generalized to physical activity as a whole. Another limitation relates to the quality assessment: the majority of studies was considered 'high' quality, which is improbable considering other literature reviews on physical activity. Therefore, it may be that we selected a too liberal cut-point for 'high quality' and/or that the QualSyst tool lacks sensitivity. Furthermore, despite the extensive search strategy conducted, relevant articles may have been missed. Although this limitation applies to all systematic literature reviews, it may be especially the case for this review because there is no commonly shared operational definition of choice architecture. The term choice architecture may thus cover many different intervention techniques that are termed differently in the literature. We attempted to minimalize those limitations by developing an operational definition of choice architecture and by including different concepts and examples related to choice architecture in our search strategy (e.g. nudging, behavioral economics, decision environment). Furthermore, the initial screening of titles was performed by only one researcher. However, this might not have influenced the results since articles were retained for the next screening phase if the researcher doubted about eligibility. Finally, we did not assess the risk of publication bias [132].

\section{Conclusions}

This systematic literature review extends the work of Forberger et al. (2019) [31] and Hollands et al. (2013) [14] by providing a systematic and comprehensive overview of studies that used choice architecture interventions to encourage physical activity or to discourage sedentary behavior in adults. The results of the current review suggest that prompting is a promising choice architecture technique to increase stair use over elevator or escalator use. For prompting, but also for other choice architecture techniques, it seems that intervention effectiveness decreases after removal of the intervention, which may be due to the fact that study participants did not (yet) develop the promoted behavior into a habit. The effectiveness of the choice architecture techniques social influence, feedback, default change and 
anchoring is hard to assess based on this review, since studies using those techniques were underrepresented. Finally, only few studies targeted sedentary behavior or other types of physical activity than stair use, such as active commuting and exercise during leisure time, which highlights the need for additional studies on those behaviors. To allow reliable assessment of behavior change and maintenance of behavior change, future studies must use objective measurement tools and a controlled experimental research design with (long-term) follow-up measures.

\section{Supplementary information}

Supplementary information accompanies this paper at https://doi.org/10. 1186/s12966-020-00942-7.

Additional file 1. Search strategy for PubMed, Embase, PsycINFO and

the Cochrane Library.

Additional file 2. Quality ratings of included studies.

\section{Abbreviations}

B: Baseline; BCTs: Behavior change techniques; BMl: Body mass index; Cl: Confidence interval; E: Experiment; F: Follow-up; I: Intervention; IE: Information environment; min: Minute(s); mths: Months; MVPA: Moderate to vigorous physical activity; OR: Odds ratio; PA: Physical activity; PE: Physical environment; PODP: Point-of-decision prompt; PRISMA: Preferred reporting items for systematic reviews and meta-analyses; QE: Quasi-experiment; SB: Sedentary behavior; SE: Social environment; T2D: Type 2 diabetes; UK: United Kingdom; USA: United States of America; wk: Week(s)

\section{Acknowledgements}

Not applicable.

\section{Authors' contributions}

All authors contributed to the conceptualization of the review. LL and LS developed the search strategy; LS conducted the database searches. LL, OD and $J J$ screened the records for eligibility. LL and JJ assessed the methodological quality of the included articles. LL conducted the data extraction and narrative synthesis and drafted the manuscript. All authors critically reviewed drafts and have read and approved the final manuscript.

\section{Funding}

No external funding was received for this research

\section{Availability of data and materials}

All data generated or analyzed during this study are included in this published article (and its supplementary information files).

\section{Ethics approval and consent to participate}

Not applicable.

\section{Consent for publication}

Not applicable.

\section{Competing interests}

The authors declare that they have no competing interests.

\section{Author details}

'Department of Public and Occupational Health, Amsterdam UMC, Vrije Universiteit Amsterdam, Amsterdam Public Health research institute, Van der Boechorststraat 7, NL-1081 BT Amsterdam, The Netherlands. ${ }^{2}$ Medical Library, VU University Amsterdam, Amsterdam, The Netherlands. ${ }^{3}$ Department of Public and Occupational Health, Amsterdam Collaboration on Health \& Safety in Sports, Amsterdam Movement Sciences, Amsterdam UMC, Vrije Universiteit Amsterdam, Amsterdam, The Netherlands.
Received: 16 October 2019 Accepted: 26 February 2020

Published online: 07 April 2020

\section{References}

1. Hallal PC, Andersen LB, Bull FC, Guthold R, Haskell W, Ekelund U, et al. Global physical activity levels: surveillance progress, pitfalls, and prospects. Lancet. 2012;380(9838):247-57.

2. Loyen A, van der Ploeg HP, Bauman A, Brug J, Lakerveld J. European sitting championship: prevalence and correlates of self-reported sitting time in the 28 European Union member states. PloS one. 2016;11(3):e0149320.

3. Lee IM, Shiroma EJ, Lobelo F, Puska P, Blair SN, Katzmarzyk PT. Effect of physical inactivity on major non-communicable diseases worldwide: an analysis of burden of disease and life expectancy. Lancet. 2012;380(9838): 219-29.

4. Wilmot EG, Edwardson CL, Achana FA, Davies MJ, Gorely T, Gray LJ, et al. Sedentary time in adults and the association with diabetes, cardiovascular disease and death: systematic review and meta-analysis. Diabetologia. 2012; 55:2895-905.

5. World Health Organization. Global health risks: mortality and burden of disease attributable to selected major risks. Geneva: World Health Organization; 2009.

6. Chau JY, Grunseit AC, Chey T, Stamatakis E, Brown WJ, Matthews CE, et al. Daily sitting time and all-cause mortality: a meta-analysis. PloS one. 2013:8(11):e80000

7. Ekelund U, Steene-Johannessen J, Brown WJ, Fagerland MW, Owen N, Powell KE, et al. Does physical activity attenuate, or even eliminate, the detrimental association of sitting time with mortality? A harmonised metaanalysis of data from more than 1 million men and women. Lancet. 2016; 388(10051):1302-10.

8. Kwasnicka D, Dombrowski SU, White M, Sniehotta F. Theoretical explanations for maintenance of behaviour change: a systematic review of behaviour theories. Health Psychol Rev. 2016;10(3):277-96.

9. Wood W, Neal DT. Healthy through habit: interventions for initiating \& maintaining health behavior change. Behav Sci Pol. 2016;2(1):71-83.

10. Thaler $H$, Sunstein $C R$. Nudge: improving decisions about health, wealth, and happiness: Yale University press; 2008.

11. Münscher $R$, Vetter $M$, Scheuerle T. A review and taxonomy of choice architecture techniques. J Behav Decis Mak. 2016;29(5):511-24.

12. Szaszi B, Palinkas A, Palfi B, Szollosi A, Aczel B. A systematic scoping review of the choice architecture movement: toward understanding when and why nudges work. J Behav Decis Mak. 2018;31(3):355-66.

13. Swinburn B, Egger G, Raza F. Dissecting obesogenic environments: the development and application of a framework for identifying and prioritizing environmental interventions for obesity. Prev Med. 1999;29(6):563-70.

14. Hollands GJ, Shemilt I, Marteau TM, Jebb SA, Kelly MP, Nakamura R, et al. Altering micro-environments to change population health behaviour: towards an evidence base for choice architecture interventions. BMC Public Health. 2013:13(1):1218.

15. Marchiori DR, Adriaanse MA, De Ridder DT. Unresolved questions in nudging research: Putting the psychology back in nudging. Soc Personal Psychol Compass. 2017;11(1):e12297.

16. Kahneman D. Thinking fast and slow. New York: Farrar, Straus and Giroux; 2011

17. Neal DT, Wood W, Quinn JM. Habits-a repeat performance. Curr Dir Psychol Sci. 2006:15(4):198-202.

18. Gigerenzer G, Gaissmaier W. Heuristic decision making. Annu Rev Psychol. 2011:62:451-82

19. Wood W, Runger D. Psychology of habit. Annu Rev Psychol. 2016;67:289-314.

20. Johnson EJ, Shu SB, Dellaert BG, Fox C, Goldstein DG, Häubl G, et al. Beyond nudges: tools of a choice architecture. Market Lett. 2012;23(2):487-504.

21. Bellicha A, Kieusseian A, Fontvieille A-M, Tataranni A, Charreire H, Oppert JM. Stair-use interventions in worksites and public settings-a systematic review of effectiveness and external validity. Prev Med. 2015;70:3-13.

22. Cialdini RB, Trost MR. Social influence: social norms, conformity and compliance. New York, US: McGraw-Hill; 1998. p. 151-92.

23. Akl EA, Oxman AD, Herrin J, Vist GE, Terrenato I, Sperati F, et al. Framing of health information messages. Cochrane Database Syst Rev. 2011;12: CD006777.

24. Gallagher KM, Updegraff JA. Health message framing effects on attitudes, intentions, and behavior: a meta-analytic review. Ann Behav Med. 2011; 43(1):101-16. 
25. Marteau TM, Ogilvie D, Roland M, Suhrcke M, Kelly MP. Judging nudging: can nudging improve population health? BMJ. 2011;342:d228.

26. Lakerveld J, Mackenbach JD, De Boer F, Brandhorst B, Broerse JE, de Bruijn G-J, et al. Improving cardiometabolic health through nudging dietary behaviours and physical activity in low SES adults: design of the supreme nudge project. BMC Public Health. 2018;18(1):899.

27. Payne JW, Bettman JR, Johnson EJ. The adaptive decision maker. Cambridge: University Press; 1993.

28. Arno A, Thomas $\mathrm{S}$. The efficacy of nudge theory strategies in influencing adult dietary behaviour: a systematic review and meta-analysis. BMC Public Health. 2016;16(1):676

29. Bucher T, Collins C, Rollo ME, McCaffrey TA, De Vlieger N, Van der Bend D, et al. Nudging consumers towards healthier choices: a systematic review of positional influences on food choice. Br J Nutr. 2016;115(12):2252-63.

30. Skov LR, Lourenco S, Hansen GL, Mikkelsen BE, Schofield C. Choice architecture as a means to change eating behaviour in self-service settings: a systematic review. Obes Rev. 2013;14(3):187-96.

31. Forberger $\mathrm{S}$, Reisch L, Kampfmann T, Zeeb H. Nudging to move: a scoping review of the use of choice architecture interventions to promote physical activity in the general population. Int J Behav Nutr Phys Act. 2019;16(1):1-14.

32. Howlett N, Trivedi D, Troop NA, Chater AM. Are physical activity interventions for healthy inactive adults effective in promoting behavior change and maintenance, and which behavior change techniques are effective? A systematic review and meta-analysis. Transl Behav Med. 2018;9(1):147-57.

33. Gollwitzer PM, Sheeran P. Implementation intentions and goal achievement: a meta-analysis of effects and processes. Adv Exp Soc Psychol. 2006;38:69-119.

34. Shamseer L, Moher D, Clarke M, Ghersi D, Liberati A, Petticrew M, et al. Preferred reporting items for systematic review and meta-analysis protocols (PRISMA-P) 2015: elaboration and explanation. BMJ. 2015;349:g7647.

35. Bramer WM, Giustini D, de Jonge GB, Holland L, Bekhuis T. De-duplication of database search results for systematic reviews in EndNote. J Med Libr Assoc. 2016;104(3):240

36. Ouzzani M, Hammady H, Fedorowicz Z, Elmagarmid A. Rayyan-a web and mobile app for systematic reviews. Systematic reviews. 2016;5(1):210.

37. Kmet LM, Cook LS, Lee RC. Standard quality assessment criteria for evaluating primary research papers from a variety of fields; 2004.

38. King A, Hekler E, Grieco L, Winter S, Sheats J, Buman M, et al. Effects of three motivationally targeted mobile device applications on initial physical activity and sedentary behavior change in midlife and older adults: a randomized trial. PloS one. 2016;(6).

39. Allais $\mathrm{O}$, Bazoche $\mathrm{P}$, Teyssier $\mathrm{S}$. Getting more people on the stairs: the impact of point-of-decision prompts. Soc Sci Med. 2017;192:18-27.

40. Andersen LL, Sundstrup E, Boysen M, Jakobsen MD, Mortensen OS, Persson R. Cardiovascular health effects of internet-based encouragements to do daily workplace stair-walks: randomized controlled trial. J Med Internet Res. 2013;15(6):e127.

41. Andersen RE, Bauman AE, Franckowiak SC, Reilley SM, Marshall AL Prompting health professionals to be activity role models-motivating stair use at the 2001 ACSM scientific meeting. J Phys Act Health. 2008:5(4):607-18.

42. Andersen RE, Franckowiak SC, Snyder J, Bartlett SJ, Fontaine KR. Can inexpensive signs encourage the use of stairs? Results from a community intervention. Ann Intern Med. 1998;129(5):363-9.

43. Avitsland A, Solbraa AK, Riiser A. Promoting workplace stair climbing: sometimes, not interfering is the best. Arch Public Health. 2017;75:2.

44. Bellicha A, Kieusseian A, Fontvieille A-M, Tataranni A, Copin N, Charreire $H$, et al. A multistage controlled intervention to increase stair climbing at work: effectiveness and process evaluation. Int J Behav Nutr Phys Act. 2016;13(1):47.

45. Blake H, Lee S, Stanton T, Gorely T. Workplace intervention to promote stairuse in an NHS setting. Int J Workplace Health Manag. 2008;1(3):162-75.

46. Blamey A, Mutrie N, Tom A. Health promotion by encouraged use of stairs. BMJ. 1995;311(7000):289-90.

47. Bond DS, Thomas JG, Raynor HA, Moon J, Sieling J, Trautvetter J, et al. BMOBILE-A smartphone-based intervention to reduce sedentary time in overweight/obese individuals: a within-subjects experimental trial. PLoS One. 2014;9(6):e100821.

48. Boutelle KN, Jeffery RW, Murray DM, Schmitz MKH. Using signs, artwork, and music to promote stair use in a public building. Am J Public Health. 2001; 91(12):2004-6.

49. Brownell KD, Stunkard AJ, Albaum JM. Evaluation and modification of exercise patterns in the natural environment. Am J Psychiatry. 1980;137(12): $1540-5$.
50. Bungum T, Meacham M, Truax N. The effects of signage and the physical environment on stair usage. J Phys Act Health. 2007;4(3):237-44.

51. Cheung PP, Chow BC, Parfitt G. Using environmental stimuli in physical activity intervention for school teachers: a pilot study. Int Electronic J Health Educ. 2008;11:47-56.

52. Coleman KJ, Gonzalez EC. Promoting stair use in a US-Mexico border community. Am J Public Health. 2001;91(12):2007-9.

53. Eckhardt MR, Kerr J, Taylor WC. Point-of-decision signs and stair use in a university worksite setting: general versus specific messages. Am J Health Promot. 2015;29(5):291-3.

54. Engbers $L H$, van Poppel MN, van Mechelen W. Modest effects of a controlled worksite environmental intervention on cardiovascular risk in office workers. Prev Med. 2007;44(4):356-62.

55. Engelen L, Gale J, Chau JY, Bauman A. Are motivational signs to increase stair use a thing of the past? A multi-building study. Health Promot J Aust. 2018;28(3):178-84

56. Eves FF, Masters RS. An uphill struggle: effects of a point-of-choice stair climbing intervention in a non-English speaking population. Int J Epidemiol. 2006;35(5):1286-90

57. Eves FF, Olander EK, Webb OJ, Griffin C, Chambers J. Likening stairs in buildings to climbing a mountain: self-reports of expected effects on stair climbing and objective measures of effectiveness. Psychol Sport Exerc 2012;13(2):170-6.

58. Eves FF, Webb OJ, Griffin C, Chambers J. A multi-component stair climbing promotional campaign targeting calorific expenditure for worksites; a quasiexperimental study testing effects on behaviour, attitude and intention. BMC Public Health. 2012;12(1):423.

59. Ford MA, Torok D. Motivational signage increases physical activity on a college campus. J Am Coll Heal. 2008;57(2):242-4.

60. Garland E, Garland V, Peters D, Doucette J, Thanik E, Rajupet S, et al. Active design in affordable housing: a public health nudge. Prev Med Rep. 2018;10:9-14.

61. Graham DJ, Linde JA, Cousins JM, Jeffery RW. Environmental modifications and 2-year measured and self-reported stair-use: a worksite randomized trial. J Prim Prev. 2013;34(6):413-22.

62. Grimstvedt ME, Kerr J, Oswalt SB, Fogt DL, Vargas-Tonsing TM, Yin Z. Using signage to promote stair use on a university campus in hidden and visible stairwells. J Phys Act Health. 2010;7(2):232-8.

63. Hodgin KL, Graham DJ. Mirror, mirror by the stairs: the impact of mirror exposure on stair versus elevator use in college students. Front Public Health. 2016:4:80

64. Kerr NA, Yore MM, Ham SA, Dietz WH. Increasing stair use in a worksite through environmental changes. Am J Health Promot. 2004;18(4):312-5.

65. Kerr J, Eves F, Carroll D. Can posters prompt stair use in a worksite environment? J Occup Health. 2001;43(4):205-7.

66. Kerr J, Eves FF, Carroll D. The influence of poster prompts on stair use: the effects of setting, poster size and content. Br J Health Psychol. 2001;6(4): $397-405$.

67. Kerr J, Eves F, Carroll D. Encouraging stair use: stair-riser banners are better than posters. Am J Public Health. 2001;91(8):1192-3.

68. Kerr J, Eves F, Carroll D. Six-month observational study of prompted stair climbing. Prev Med. 2001;33(5):422-7.

69. Kwak L, Kremers SP, Van Baak M, Brug J. A poster-based intervention to promote stair use in blue-and white-collar worksites. Prev Med. 2007;45(2-3):177-81.

70. Lewis AL, Eves FF. Testing the theory underlying the success of point-ofchoice prompts: a multi-component stair climbing intervention. Psychol Sport Exerc. 2012;13(2):126-32.

71. Lewis A, Eves F. Prompt before the choice is made: effects of a stairclimbing intervention in university buildings. Br J Health Psychol. 2012;17(3): 631-43

72. Lewis AL, Eves FF. Specific effects of a calorie-based intervention on stair climbing in overweight commuters. Ann Behav Med. 2011;42(2):257-61.

73. Marshall A, Bauman A, Patch C, Wilson J, Chen J. Can motivational signs prompt increases in incidental physical activity in an Australian health-care facility? Health Educ Res. 2002;17(6):743-9.

74. Moloughney BW, Bursey GE, Fortin RB, Morais MG, Dang KT. A multicomponent intervention to encourage stair use in municipal buildings. Am J Health Promot. 2018:33(1):57-69.

75. Müller-Riemenschneider F, Nocon M, Reinhold T, Willich SN. Promotion of physical activity using point-of-decision prompts in Berlin underground stations. Int J Environ Res Public Health. 2010;7(8):3063-70. 
76. Olander EK, Eves FF. Effectiveness and cost of two stair-climbing interventions-less is more. Am J Health Promot. 2011;25(4):231-6.

77. Olander EK, Eves FF, Puig-Ribera A. Promoting stair climbing: stair-riser banners are better than posters ... sometimes. Prev Med. 2008;46(4):308-10.

78. Puig-Ribera A, Eves FF. Promoting stair climbing in Barcelona: similarities and differences with interventions in English-speaking populations. Eur J Pub Health. 2009;20(1):100-2.

79. Slaunwhite JM, Smith SM, Fleming MT, Fabrigar LR. Using normative messages to increase healthy behaviours. Int J Workplace Health Manag 2009;2(3):231-44.

80. Swenson T, Siegel M. Increasing stair use in an office worksite through an interactive environmental intervention. Am J Health Promot. 2013;27(5):323-9.

81. Vanden Auweele Y, Boen F, Schapendonk W, Dornez K. Promoting stair use among female employees: the effects of a health sign followed by an email. J Sport Exerc Psychol. 2005;27(2):188-96.

82. Webb OJ, Cheng T-F. An informational stair climbing intervention with greater effects in overweight pedestrians. Health Educ Res. 2010;25(6):93644.

83. Webb OJ, Eves FF. Promoting stair climbing: intervention effects generalize to a subsequent stair ascent. Am J Health Promot. 2007;22(2):114-9..

84. Webb OJ, Eves FF. Effects of environmental changes in a stair climbing intervention: generalization to stair descent. Am J Health Promot. 2007; 22(1):38-44.

85. Webb OJ, Eves FF. Promoting stair use: single versus multiple stair-riser messages. Am J Public Health. 2005;95(9):1543-4.

86. Arora R, Stoner C, Arora A. Using framing and credibility to incorporate exercise and fitness in individuals' lifestyle. J Consum Market. 2006;23(4): 199-207.

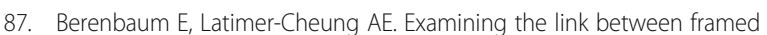
physical activity ads and behavior among women. J Sport Exerc Psychol. 2014;36(3):271-80.

88. Cho J, Chun JW, Lee MJ. Impacts of message framing and social distance in health campaign for promoting regular physical exercise. J Health Commun. 2018;23(9):824-35

89. Cohen A, Perozich A, Rajan R, Persky S, Parisi J, Bowie J, et al. Framed, interactive theory-driven texting: effects of message framing on health behavior change for weight loss. Fam Community Health. 2017:40(1):43-51.

90. Daffu-O'Reilly A, O'Connor D, Lawton R. Testing message framing to increase physical activity among British south Asians. Health Psychol Behav Med. 2017;5(1):372-89.

91. de Bruijn GJ, Out K, Rhodes RE. Testing the effects of message framing, kernel state, and exercise guideline adherence on exercise intentions and resolve. Br J Health Psychol. 2014;19(4):871-85.

92. Gray JB, Harrington NG. Narrative and framing: a test of an integrated message strategy in the exercise context. J Health Commun. 2011;16(3): 264-81.

93. Jones L, Sinclair R, Rhodes R, Courneya K. Promoting exercise behaviour: an integration of persuasion theories and the theory of planned behaviour. $\mathrm{Br} J$ Health Psychol. 2004;9:505-21.

94. Jones LW, Sinclair RC, Courneya KS. The effects of source credibility and message framing on exercise intentions, behaviors and attitudes: an integration of the elaboration likelihood model and prospect theory. J Appl Soc Psychol. 2003;33(1):179-96.

95. Kozak AT, Nguyen C, Yanos BR, Fought A. Persuading students to exercise: what is the best way to frame messages for normal-weight versus overweight/obese university students? J Am Coll Heal. 2013;61(5):264-73..

96. Latimer AE, Rench TA, Rivers SE, Katulak NA, Materese SA, Cadmus $L$, et al. Promoting participation in physical activity using framed messages: an application of prospect theory. Br J Health Psychol. 2008;13:659-81.

97. Li KK, Ng L, Cheng ST, Fung HH. Reverse message-framing effects on accelerometer-assessed physical activity among older outpatients with type 2 diabetes. J Sport Exerc Psychol. 2017;39(3):222-7.

98. Li KK, Cheng ST, Fung HH. Effects of message framing on self-report and accelerometer-assessed physical activity across age and gender groups. J Sport Exerc Psychol. 2013;36(1):40-51.

99. Lithopoulos A, Young BW. Sport gain-framed messages, possible selves, and their effects on adults' interest, intentions, and decision to register in sport. Int J Sport Exerc Psychol. 2018;16(3):313-26.

100. McCall LA, Ginis KAM. The effects of message framing on exercise adherence and health beliefs among patients in a cardiac rehabilitation program. J Appl Biobehav Res. 2004;9(2):122-35.
101. Morris B, Lawton R, McEachan R, Hurling R, Conner M. Changing selfreported physical activity using different types of affectively and cognitively framed health messages, in a student population. Psychol Health Med. 2016;21(2):198-207.

102. Notthoff N, Klomp P, Doerwald F, Scheibe S. Positive messages enhance older adults' motivation and recognition memory for physical activity programmes. Eur J Ageing. 2016;13(3):251-7.

103. Notthoff N, Carstensen LL. Positive messaging promotes walking in older adults. Psychol Aging. 2014;29(2):329-41.

104. Ratcliff CL, Jensen JD, Scherr CL, Krakow M, Crossley K. Loss/gain framing, dose, and reactance: a message experiment. Risk Anal. 2019;39(12):2640-52.

105. Vanroy J, Seghers J, van Uffelen J, Boen F. Can a framed intervention motivate older adults in assisted living facilities to exercise? BMC Geriatr. 2019;19(1):46.

106. van't Riet J, Ruiter RA, Werrij MQ, de Vries H. Investigating message-framing effects in the context of a tailored intervention promoting physical activity. Health Educ Res. 2009:25(2):343-54

107. Wirtz JG, Kulpavaropas $\mathrm{S}$. The effects of narrative and message framing on engagement and eating intention among a sample of adult Hispanics. J Nutr Educ Behav. 2014;46(5):396-400.

108. Zenko Z, Ekkekakis P, Kavetsos G. Changing minds: bounded rationality and heuristic processes in exercise-related judgments and choices. Sport Exerc Perform Psychol. 2016;5(4):337-51.

109. Cooley PD, Foley SJ, Magnussen CG. Increasing stair usage in a professional workplace: a test of the efficacy of positive and negative message prompts to change pedestrian choices. Health Promot J Aust. 2008;19(1):64-7.

110. Van Hoecke A-S, Seghers J, Boen F. Promoting stair climbing in a worksite and public setting: are footprints enough? Am J Health Promot. 2018;32(3): 527-35.

111. Gorin AA, Raynor HA, Fava J, Maguire K, Robichaud E, Trautvetter J, et al. Randomized controlled trial of a comprehensive home environmentfocused weight-loss program for adults. Health Psychol. 2013;32(2):128-37.

112. Van Calster L, Van Hoecke A-S, Octaef A, Boen F. Does a video displaying a stair climbing model increase stair use in a worksite setting? Public Health. 2017;149:11-20.

113. Zhang J, Brackbill D, Yang S, Centola D. Efficacy and causal mechanism of an online social media intervention to increase physical activity: results of a randomized controlled trial. Prev Med Rep. 2015;2:651-7.

114. Howie EK, Young DR. Step it UP: a multicomponent intervention to increase stair use in a university residence building. Am J Health Promot. 2011;26(1):2-5.

115. Patel MS, Small DS, Harrison JD, Fortunato MP, Oon AL, Rareshide CAL, et al. Effectiveness of behaviorally designed Gamification interventions with social incentives for increasing physical activity among overweight and obese adults across the United States: the STEP UP randomized clinical trial. JAMA Intern Med. 2019;179(12):1624-32

116. Tullar JM, Walker TJ, Page TF, Taylor WC, Roman R, Amick BC 3rd. Evaluation of a worksite-based Small group team challenge to increase physical activity. Am J Health Promot. 2019;33(2):259-66.

117. Zhang J, Brackbill D, Yang S, Becker J, Herbert N, Centola D. Support or competition? How online social networks increase physical activity: a randomized controlled trial. Prev Med Rep. 2016:4:453-8.

118. Patel M, Benjamin E, Volpp K, Fox C, Small D, Massaro J, et al. Effect of a social incentive-based gamification intervention using wearable devices and smartphones on physical activity: the befit randomized clinical trial. JAMA Intern Med. 2017;32(2):S172.

119. Strath SJ, Swartz AM, Parker SJ, Miller NE, Grimm EK, Cashin SE. A pilot randomized controlled trial evaluating motivationally matched pedometer feedback to increase physical activity behavior in older adults. J Phys Act Health. 2011:8:S267-74.

120. Anson D, Madras D. Do low step count goals inhibit walking behavior: a randomized controlled study. Clin Rehabil. 2016;30(7):676-85.

121. Venema TAG, Kroese FM, De Ridder DTD. I'm still standing: a longitudinal study on the effect of a default nudge. Psychol Health. 2017;33(5):669-81.

122. Aarts $H$, Dijksterhuis A. Habits as knowledge structures: automaticity in goaldirected behavior. J Pers Soc Psychol. 2000;78(1):53.

123. Craig CL, Marshall AL, Sjöström M, Bauman AE, Booth ML, Ainsworth BE, et al. International physical activity questionnaire: 12-country reliability and validity. Med Sci Sports Exerc. 2003;35(8):1381-95.

124. Verplanken B, Wood W. Interventions to break and create consumer habits. J Public Policy Mark. 2006;25(1):90-103. 
125. Kaushal N, Rhodes RE. Exercise habit formation in new gym members: a longitudinal study. J Behav Med. 2015;38(4):652-63.

126. Lally P, Van Jaarsveld CH, Potts HW, Wardle J. How are habits formed: Modelling habit formation in the real world. Eur I Soc Psychol. 2010;40(6): 998-1009.

127. Williams KD. Ostracism. Annu Rev Psychol. Annu Rev Public Health. 2007;58:425-52.

128. Baumeister RF, Leary MR. The need to belong: desire for interpersonal attachments as a fundamental human motivation. Psychol Bull. 1995;117(3):497.

129. Turner J, Perkins HW, Bauerle J. Declining negative consequences related to alcohol misuse among students exposed to a social norms marketing intervention on a college campus. J Am Coll Heal. 2008;57(1):85-94.

130. Biswas A, Oh PI, Faulkner GE, Bajaj RR, Silver MA, Mitchell MS, et al. Sedentary time and its association with risk for disease incidence, mortality, and hospitalization in adults: a systematic review and meta-analysis. Ann Intern Med. 2015;162(2):123-32.

131. Michie S, Richardson M, Johnston M, Abraham C, Francis J, Hardeman W, et al. The behavior change technique taxonomy (v1) of 93 hierarchically clustered techniques: building an international consensus for the reporting of behavior change interventions. Ann Behav Med. 2013;46(1):81-95.

132. Dwan K, Gamble C, Williamson PR, Kirkham JJ. Systematic review of the empirical evidence of study publication bias and outcome reporting bias—an updated review. PloS one. 2013;8(7):e66844.

\section{Publisher's Note}

Springer Nature remains neutral with regard to jurisdictional claims in published maps and institutional affiliations.

Ready to submit your research? Choose BMC and benefit from:

- fast, convenient online submission

- thorough peer review by experienced researchers in your field

- rapid publication on acceptance

- support for research data, including large and complex data types

- gold Open Access which fosters wider collaboration and increased citations

- maximum visibility for your research: over $100 \mathrm{M}$ website views per year

At $\mathrm{BMC}$, research is always in progress.

Learn more biomedcentral.com/submissions 